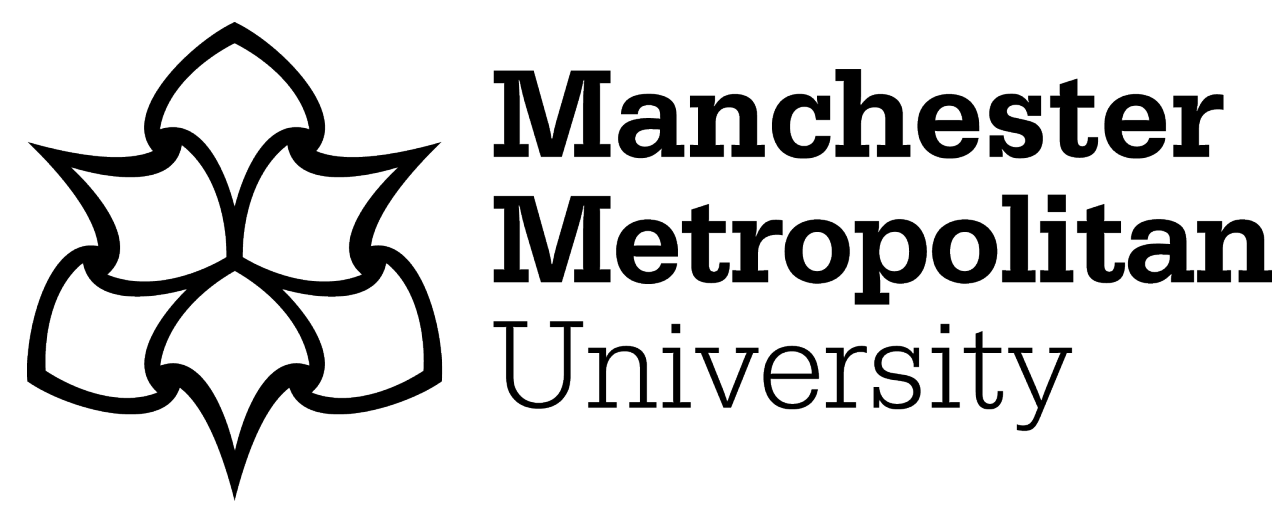

Langley, SK, Vignesh, KR, Gupta, T, Gartshore, CJ, Rajaraman, G, Forsyth, CM and Murray, KS (2019) New examples of triangular terbium(iii) and holmium(iii) and hexagonal dysprosium(iii) single molecule toroics. Dalton Transactions, 48 (41). pp. 15657-15667. ISSN 1477-9226

Downloaded from: https://e-space.mmu.ac.uk/625955/

Version: Accepted Version

Publisher: Royal Society of Chemistry

DOI: https://doi.org/10.1039/c9dt02419k

Please cite the published version 


\title{
New Examples of Triangular and Hexagonal Terbium(III), Dysprosium(III) and Holmium(III) Single Molecule Toroics
}

Received 00th January 20xx, Accepted 00th January 20xx

DOI: $10.1039 / \times 0 x \times 00000 x$

www.rsc.org/

\author{
Stuart K. Langley ${ }^{a^{*}}$, Kuduva R. Vignesh ${ }^{\mathrm{b}}$, Tulika Gupta ${ }^{\mathrm{b}}$, Christopher J. Gartshore ${ }^{\mathrm{c}}$, Gopalan \\ Rajaraman $^{\mathrm{b} *}$ and Keith S. Murray ${ }^{\mathrm{c}^{*}}$
}

\begin{abstract}
The structural, magnetic and theoretical aspects are described for three triangular lanthanide complexes, $\left[\mathrm{Tb}^{\prime \prime \prime}{ }_{3}(\mathrm{OH})\left(\text { teaH }_{2}\right)_{3}(\text { paa })_{3}\right] \mathrm{Cl}_{2}(\mathbf{1}),\left[\mathrm{Dy}^{\prime \prime \prime}{ }_{3}(\mathrm{OH})\left(\text { teaH }_{2}\right)_{3}(\text { paa })_{3}\right] \mathrm{Cl}_{2}(\mathbf{2})$ and $\left[\mathrm{Ho}^{\prime \prime \prime}{ }_{3}(\mathrm{OH})\left(\mathrm{teaH}_{2}\right)_{3}(\mathrm{paa})_{3}\right] \mathrm{Cl}_{2}(3)$, and a hexanuclear wheel of formula $\left[\mathrm{Dy}^{\mathrm{III}}{ }_{6}(\mathrm{pdeaH})_{6}\left(\mathrm{NO}_{3}\right)_{6}\right](4)$ [teaH $\mathrm{H}_{3}=$ triethanolamine, paaH = N-(2-pyridyl)-acetoacetamide and pdeaH $\mathrm{H}_{3}=3-[\mathrm{bis}(2-$ hydroxyethyl)amino]propan-1-ol]. Each complex displays single molecule toroidal behaviour as rationalised using high-level $a b$ initio calculations. Complexes $\mathbf{2}$ and $\mathbf{3}$ are the first examples of mixed moment single molecule toroidal complexes featuring non-Kramers ions.
\end{abstract}

\section{Introduction}

Since the pioneering work by Powell et al. ${ }^{1}$ on toroidal dysprosium(III) triangular complexes, the field of single molecule toroics (SMTs) has grown rapidly from both experimental and theoretical viewpoints. ${ }^{1-2}$ Some highlights include the discovery of toroidal magnetism in planar rings such as $\left\{\mathrm{Dy}_{4}\right\}^{3}$ and $\left\{\mathrm{Dy}_{6}\right\}^{4}$, nonplanar (cubanoid)) $\left\{\mathrm{Dy}_{4}\right\}^{5}$ and mixed $d$-f-block species such as $\left\{\mathrm{Cu}^{\prime \prime} \mathrm{Dy}_{3}\right\}$ chains $^{6}$, large $\left\{\mathrm{Cu}_{6}{ }_{6} \mathrm{Dy}{ }_{6}\right\}$ rings, $^{7}$ and 'double triangular' $\left\{\mathrm{Dy}_{3} \mathrm{Cr}^{\mathrm{III}} \mathrm{Dy} \mathrm{y}_{3}\right\}$ heptanuclear clusters, ${ }^{8}$ the last example showing the rare phenomenon of ferrotoroidal behaviour. Toroidal moments are majorly reported for Dy"II complexes, however, we have recently reported SMTs containing Tb"I and Ho $\mathrm{Oo}^{\text {III }}$ ions. ${ }^{4 \mathrm{~b}, 9}$ The growth in the subject is not only because of the fundamental knowledge to be gained about SMTs but also because of the possible applications in areas such as quantum information processing, ${ }^{10}$ high-density data storage and as nanoscale devices such as molecular spin valves and spin transistors. ${ }^{10 a, 11}$ Molecular based devices offer the advantage of tuneable properties, whereby the electronic structure of the molecule can be influenced by the coordination environment of the lanthanide ion, which can be exploited to modify the physical properties.

One of the chemico-structural design problems in SMT chemistry is

\footnotetext{
a. School of science and the environment, Division of Chemistry, Manchester Metropolitan University, Manchester, M15 6BH, UK. Email: s.langley@mmu.ac.uk b. Department of Chemistry, Indian Institute of Technology Bombay, Mumbai400076, India. Email : rajaraman@chem.iitb.ac.in

c. School of Chemistry, Monash University, Clayton, Victoria 3800, Australia. Email: keith.murray@monash.edu

\$ Dedicated to Professor Annie K. Powell on the celebration of her $60^{\text {th }}$ birthday and her contributions to molecular magnetism and inorganic chemistry.

Electronic Supplementary Information (ESI) available: Additional molecular structures, structural parameter tables, magnetic plots and calculated values. See DOI: 10.1039/x0xx00000x
}

to design ligand and bridging moieties, in dysprosium ring complexes, that will lead unambiguously to toroidal behaviour, proven by magnetic and computational data. In the present work we describe the structures and magnetism of three triangular complexes, $\left[\mathrm{Tb}^{\prime \prime \prime}{ }_{3}(\mathrm{OH})\left(\text { teaH }_{2}\right)_{3}(\text { paa })_{3}\right] \mathrm{Cl}_{2} \cdot \mathrm{MeCN} \cdot 4 \mathrm{H}_{2} \mathrm{O}$

(1),

$\left[\right.$ Dy $\left.^{\prime \prime \prime}{ }_{3}(\mathrm{OH})\left(\text { teaH }_{2}\right)_{3}(\text { paa })_{3}\right] \mathrm{Cl}_{2} \cdot \mathrm{MeCN} \cdot 4 \mathrm{H}_{2} \mathrm{O}$

(2) and

$\left[\mathrm{Ho}_{3}{ }_{3}(\mathrm{OH})\left(\mathrm{teaH}_{2}\right)_{3}(\mathrm{paa})_{3}\right] \mathrm{Cl}_{2} \cdot \mathrm{MeCN} \cdot 4 \mathrm{H}_{2} \mathrm{O}(3)$, and a new hexagonal 6- ring compound $\left[\mathrm{Dy}^{\prime \prime \prime} 6(\mathrm{pdeaH})_{6}\left(\mathrm{NO}_{3}\right)_{6}\right] \cdot 5 \mathrm{H}_{2} \mathrm{O}$ (4) $\left[\mathrm{teaH}_{3}=\right.$ triethanolamine, paaH $=\mathrm{N}$-(2-pyridyl)-acetoacetamide and $\mathrm{pdeaH}_{3}=$ 3-[bis(2-hydroxyethyl)amino]propan-1-ol (Figure 1)]. We show via a combination of experimental and theoretical $a b$ initio calculations that each complex display a rotating magnetic moment in the exchange coupled ground magnetic state, thus revealing SMT behaviour.

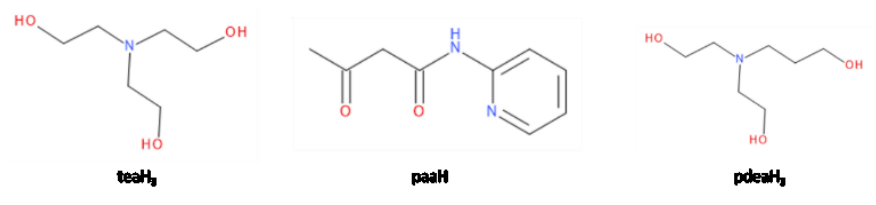

Figure 1. Molecular structure of ligands - teaH $\mathrm{H}_{3}$, paaH and pdeaH $\mathrm{p}_{3}$.

\section{Experimental Section}

\section{General Information}

The reactions were carried out under aerobic conditions. Chemicals and solvents were obtained from commercial sources and used without further purification.

\section{Synthesis of $\left[\mathrm{Tb}^{\prime \prime \prime}{ }_{3}(\mathrm{OH})\left(\text { teaH }_{2}\right)_{3}(\text { paa })_{3}\right] \mathrm{Cl}_{2} \cdot \mathrm{MeCN} \cdot 4 \mathrm{H}_{2} \mathrm{O}$ (1)}

$\mathrm{TbCl}_{3} \cdot 6 \mathrm{H}_{2} \mathrm{O}(0.38 \mathrm{~g}, 1.0 \mathrm{mmol})$ was dissolved in $\mathrm{MeOH} / \mathrm{MeCN}(1: 1,20$ $\mathrm{mL})$, followed by the addition of triethanolamine $(0.13 \mathrm{~mL}, 1.0$ mmol), $\mathrm{N}$-(2-pyridyl)-acetoacetamide $(0.18 \mathrm{~g}, 1.0 \mathrm{mmol})$ and triethylamine $(0.55 \mathrm{~mL}, 4.0 \mathrm{mmol})$ which resulted in a pale yellow solution. This was stirred for 6 hours, after which the solution was layered with diethylether $\left(\mathrm{Et}_{2} \mathrm{O}\right)$. Within 1-2 days block-shaped crystals of 1 had formed, in approximate yield of 57\%. Anal. Calc. for 1: $\mathrm{Tb}_{3} \mathrm{C}_{47} \mathrm{H}_{81} \mathrm{O}_{20} \mathrm{~N}_{10} \mathrm{Cl}_{2}: \mathrm{C}, 34.13 ; \mathrm{H}, 4.94 ; \mathrm{N}, 8.47$. Found: $\mathrm{C}, 34.24 ; \mathrm{H}$, 4.99; N, 8.63\%.

\section{Synthesis of $\left[\mathrm{Dy}^{\prime \prime \prime}{ }_{3}(\mathrm{OH})\left(\mathrm{teaH}_{2}\right)_{3}(\mathrm{paa})_{3}\right] \mathrm{Cl}_{2} \cdot \mathrm{MeCN} \cdot 4 \mathrm{H}_{2} \mathrm{O}$ (2).}

The synthesis for 1 was followed with $\mathrm{DyCl}_{3} \cdot 6 \mathrm{H}_{2} \mathrm{O}(1 \mathrm{mmol})$ used in place of $\mathrm{TbCl}_{3} \cdot 6 \mathrm{H}_{2} \mathrm{O}$. Within 1-2 days block-shaped crystals of $\mathbf{2}$ had formed, in approximate yield of $63 \%$. Anal. Calc. for 2: Dy ${ }_{3} \mathrm{C}_{47} \mathrm{H}_{81} \mathrm{O}_{20} \mathrm{~N}_{10} \mathrm{Cl}_{2}$ : C, 33.91; $\mathrm{H}, 4.90 ; \mathrm{N}, 8.41$. Found: $\mathrm{C}, 33.60 ; \mathrm{H}$, $4.87 ; \mathrm{N}, 8.31 \%$.

\section{Synthesis of $\left[\mathrm{Ho}^{\prime \prime \prime}{ }_{3}(\mathrm{OH})\left(\mathrm{teaH}_{2}\right)_{3}(\mathrm{paa})_{3}\right] \mathrm{Cl}_{2} \cdot \mathrm{MeCN} \cdot 4 \mathrm{H}_{2} \mathrm{O}$ (3).}


The synthesis for 1 was followed with $\mathrm{HoCl}_{3} \cdot 6 \mathrm{H}_{2} \mathrm{O}(1 \mathrm{mmol})$ used in place of $\mathrm{TbCl}_{3} \cdot 6 \mathrm{H}_{2} \mathrm{O}$. Within 1-2 days block-shaped crystals of $\mathbf{3}$ had formed, in approximate yield of $63 \%$. Anal. Calc. for 3: $\mathrm{Ho}_{3} \mathrm{C}_{47} \mathrm{H}_{81} \mathrm{O}_{20} \mathrm{~N}_{10} \mathrm{Cl}_{2}$ : C, 33.76; $\mathrm{H}, 4.88 ; \mathrm{N}, 8.38$. Found: $\mathrm{C}, 33.87 ; \mathrm{H}$, 4.76; $\mathrm{N}, 8.56 \%$.

\section{Synthesis of 3-[bis(2-hydroxyethyl)amino]propan-1-ol (pdeaH $\left.\mathrm{H}_{3}\right)$}

Diethanolamine $(5.25 \mathrm{~g}, 53 \mathrm{mmol})$, 3-chloropropanol (5.0 g, 53 $\mathrm{mmol})$ and $\mathrm{KOH}\left(3.0 \mathrm{~g}, 53 \mathrm{mmol}\right.$ were refluxed in $\mathrm{H}_{2} \mathrm{O}(25 \mathrm{ml})$ for 12 hours. After this time the reaction was cooled and the solid filtered. The solid was rinsed with a minimal amount of cold $\mathrm{EtOH}$ and the solvent was evaporated. The product was obtained as a viscous yellow oil.

\section{Synthesis of $\left[\mathrm{Dy}^{\prime \prime \prime} 6(\mathrm{pdeaH})_{6}\left(\mathrm{NO}_{3}\right)_{6}\right] \cdot 5 \mathrm{H}_{2} \mathrm{O}$ (4).}

$\operatorname{Dy}\left(\mathrm{NO}_{3}\right)_{3} \cdot 6 \mathrm{H}_{2} \mathrm{O}(0.44 \mathrm{~g}, 1.0 \mathrm{mmol})$ was dissolved in $\mathrm{MeOH} / \mathrm{CH}_{2} \mathrm{Cl}_{2}$ $(1: 3, \quad 20 \mathrm{~mL})$, followed by the addition of 3-[bis(2hydroxyethyl)amino]propan-1-ol $(0.13 \mathrm{~mL}, 1.0 \mathrm{mmol})$ and triethylamine $(0.55 \mathrm{~mL}, 4.0 \mathrm{mmol})$ which resulted in a colourless solution. This was stirred for 6 hours, after which the solution was filtered to remove any precipitate and layered with diethylether ( $\left.\mathrm{Et}_{2} \mathrm{O}\right)$. Within 1-2 days block-shaped crystals of $\mathbf{4}$ had formed, in approximate yield of $23 \%$. Anal. Calc. for 4 : $\mathrm{Dy}_{6} \mathrm{C}_{42} \mathrm{H}_{102} \mathrm{O}_{42} \mathrm{~N}_{12}: \mathrm{C}$, $20.85 ; \mathrm{H}, 4.24 ; \mathrm{N}, 6.94$. Found: $\mathrm{C}, 21.21 ; \mathrm{H}, 4.45 ; \mathrm{N}, 7.32 \%$.

X-ray Crystallography. X-ray measurements for $\mathbf{1}$ - $\mathbf{4}$ were performed at $123 \mathrm{~K}$ using a Bruker Smart Apex X8 diffractometer using Mo $\mathrm{K}_{\alpha}$ radiation. The data collection and integration were performed within SMART and SAINT+ software programs and corrected for absorption using the Bruker SADABS program. Compounds $\mathbf{1}$ - $\mathbf{4}$ were solved by direct methods (SHELXS-97), 12 and refined (SHELXL-97) ${ }^{13}$ by full least matrix least-squares on all $F^{2}$ data. ${ }^{14}$ Crystallographic data and refinement parameters are summarized in Table S1. Crystallographic details are available in the Supporting Information (SI) in CIF format. CCDC numbers 1915658 (1), 929918 (2), 1915657 (3) and 1915659 (4). These data can be obtained free of charge from the Cambridge Crystallographic Data Centre via www.ccdc.cam.ac.uk/data request/cif.

Magnetic Measurements. The magnetic susceptibility measurements were carried out on a Quantum Design SQUID magnetometer MPMS-XL 7 operating between 1.8 and $300 \mathrm{~K}$ for dcapplied fields ranging from $0-5 \mathrm{~T}$. Microcrystalline samples were dispersed in Vaseline in order to avoid torquing of the crystallites. The sample mulls were contained in a calibrated gelatine capsule held at the centre of a drinking straw that was fixed at the end of the sample rod. Alternating current (ac) susceptibility measurements were carried out under an oscillating ac field of 3.5 Oe and frequencies ranging from 0.1 to $1500 \mathrm{~Hz}$.

\section{Computational Details}

The magnetic properties of all the $\mathrm{Ln}$ "II centres in complexes 1-4 were studied by fragment $a b$ initio calculations using MOLCAS 8.0. ${ }^{15}$ At par with the underlying limitations in MOLCAS 8.0, we have undertaken calculations only on individual single paramagnetic metal sites at a time, considering individual paramagnetic metal fragments. However, accounting the crucial role imposed by neighbouring metal centres, for 1-3, three types of calculations were undertaken. For each fragmented calculation, one $\mathrm{Ln}^{\mathrm{II}}$ ion of interest was kept intact, while the other two sites were substituted by diamagnetic La"l' ions. All the foregoing calculations were carried out on X-ray crystal structures (1-3) employing the [ANO-RCC...7s6p4d2f] ${ }^{16}$ basis set for Tb"'I, Dy"I', Ho"l' and La'l' atoms, [ANO-RCC...2s] basis set for $\mathrm{H}$, and [ANO-RCC...3s2p] basis set for $\mathrm{C}, \mathrm{N}, \mathrm{O}$ atoms as inscribed in MOLCAS suite. Using multiconfigurational approach relativistic effects are taken into account on the basis of the Douglas-Kroll Hamiltonian. ${ }^{17}$ The spin-free Eigen states are achieved by the Complete Active Space Self-Consistent Field (CASSCF) method (see ESI for more information about computational details of complexes $1-3) .{ }^{18} \operatorname{In} 4$, even though all the Dy"lI ions have the same ligand environment, we performed calculations on all six Dy III ions to ensure that we capture all the intricate details of the structure. Since the complete molecule is too large to perform these types of calculations, we have fragmented the $\left\{\mathrm{Dy}_{6}\right\}$ wheel into a trinuclear species and have substituted neighbouring ions with a diamagnetic Lu'll ion. The model fragment is shown in Figure S1 of ESI. We have employed the [ANO-RCC... $8 \mathrm{~s} 7 \mathrm{p} 5 \mathrm{~d} 3 \mathrm{f} 2 \mathrm{~g} 1 \mathrm{~h}$.] basis set for Dy"ll atoms, the [ANO-RCC...3s 2p.] basis set for $\mathrm{C}$ atoms, the [ANO-RCC...2s.] basis set for $\mathrm{H}$ atoms, the [ANORCC...3s2p1d.] basis set for $\mathrm{N}$ atoms, the [ANO-RCC...7s6p4d2f.] basis set for the Lu atom, and the [ANO-RCC...3s $2 \mathrm{p} 1 \mathrm{~d}$.] basis set for $\mathrm{O}$ atoms in complex 4 . Here, we included nine electrons across seven $4 \mathrm{f}$ orbitals of the Dy ${ }^{3+}$ ion. In the first step, we run a guessorb calculation using Seward module to create the starting guess orbitals of a metal ion. Harnessing these guess orbitals, we have selected the active space based on the number of active electrons in the number of active orbitals using SA-CASSCF approach to determine spin-free wave functions and energies. Here, 21 roots in the Configuration Interaction $(\mathrm{Cl})$ procedure were computed for $\mathrm{Dy}^{3+}$ ion. Moreover, these computed SO states have been considered into the SINGLE_ANISO ${ }^{19}$ program to compute the $g$-tensors. Crystal-field parameters have been extracted using the SINGLE_ANISO code, as implemented in MOLCAS 8.0.

The exchange/dipolar interactions between neighbouring Ln $^{\text {III-Ln }} \mathrm{LII}^{\prime \prime}$ ions of $\mathbf{1}-\mathbf{4}$ have been computed by fitting with the experimental magnetic data $4 c, 6,20$ using the Lines model ${ }^{21}$ as embedded in POLY_ANISO routine. ${ }^{22}$

The exchange Hamiltonian adapted for complexes $\mathbf{1 - 4}$ are shown below.

$$
\widehat{H}_{e x}=-\sum_{i=1}^{3} J_{i} \cdot S_{i} \cdot S_{i+1}
$$

(here $J_{i}=J_{i}$ dipolar $+J_{i}{ }^{e x c h}$; i.e. $J_{i}$ are the total magnetic interaction of the calculated $J_{i}$ dipolar and fitted $J_{i}$ exch parameters; this describes the interaction between all the neighbouring metal centres).

\section{Results and Discussion}

X-ray crystallography reveals that compounds $\mathbf{1}-\mathbf{3}$ crystallize in the trigonal space group $P-3$, with the asymmetric unit (ASU) containing 
one $\mathrm{Ln}^{\prime \prime \prime}$ ion, one (teaH) ${ }^{2-}$, one (paa)- and one-third of the (OH)- ligand. Two $\mathrm{Cl}^{-}$anions are also found in the ASU each at one third occupancy. Compounds $\mathbf{1}-\mathbf{3}$ are isostructural and thus the description of $\mathbf{1}$ will be given. The molecule is trinuclear with the metallic core displaying a triangular arrangement of $\mathrm{Tb}^{\mathrm{III}}$ ions (see Figure 2). These ions are bridged together via a single $\mu_{3}$ hydroxide ligand and three singly deprotonated (teaH) ${ }^{2-}$ ligands. The three (teaH) ${ }^{2-}$ ligands all display the $\mu_{2}: \eta^{2}: \eta^{1}: \eta^{1}: \eta^{1}$ bonding mode, bridging via one O-atom, while the two protonated $\mathrm{O}$-atoms and the $\mathrm{N}$-atom chelate. The three (paa) ligands that are present also chelate via the $\beta$-diketonate functionality, each to one Tb"II ion, with the pyridyl group being noncoordinating. Two chloride counterions are also found, the first lying below the plane of the triangle and is found to be $\mathrm{H}$-bonding to the one of the protonated $\mathrm{O}$-atoms of each (teaH) ${ }^{2-}$ ligand. The second chloride also forms a $\mathrm{H}$-bond, in this case to the amine group associated with the (paa)- ligand. Intra-molecular $\mathrm{H}$-bond interactions are observed between the second protonated $\mathrm{O}$-atom of the (teaH) $)^{2-}$ ligands and the pyridyl groups of the paa- ligand. The three $\mathrm{Tb}^{\text {III }}$ ions are all eight coordinate with distorted square antiprismatic geometries. The average $T b-L_{N, O}$ distance is found to be $2.39 \AA$ ( 2.38 for $\mathbf{2}$ (Dy) and 2.37 for $\mathbf{3}$ (Ho)). The molecules pack in such a way that large channels are observable, which are filled with the disordered solvent water and MeCN molecules (Figure S2). Selected bond lengths for $\mathbf{1} \mathbf{- 3}$ are given in Table S2.
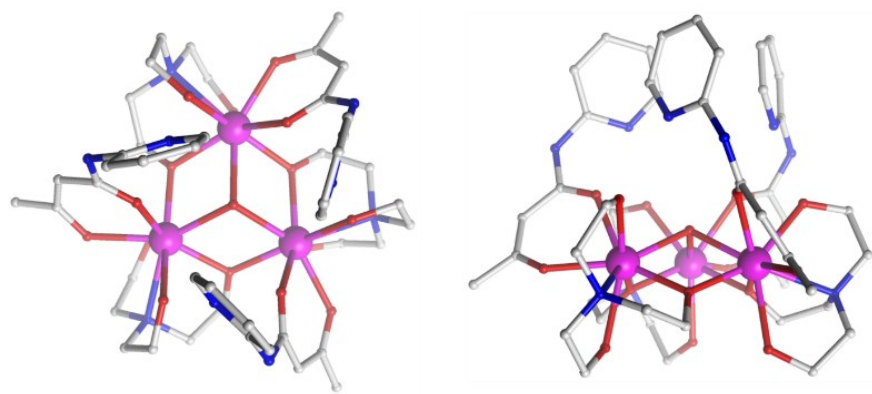

Figure 2. Molecular structure of 1, (left) top view, (right) side view. Colour scheme Dy'II, pink; O, red; N, blue; C, grey, the H-atoms and chloride counter ions are omitted for clarity. The same structure is applicable for $\mathbf{2}$ and $\mathbf{3}$.

Single crystal $X$-ray analysis reveal that compound $\mathbf{4}$ crystallizes in the trigonal space group, $R-3$, with the asymmetric unit containing one Dy"II ion. It is found to be a hexanuclear species containing six Dy'II ions, with a planar wheel metallic core structure (Figure 3 ). The wheel is stabilized by six (pdeaH $)^{2-}$ and six nitrate ligands. Each of the six (pdeaH) ${ }^{2-}$ ligands coordinate to a Dy ${ }^{\text {III }}$ site via the $\mathrm{N}$-atom. The two deprotonated $\mathrm{O}$-atoms, which constitute the 2-carbon chain arms, then chelate and bridge from the Dy"l' site to two adjacent Dy"l' ions. Each ligand therefore bridges to three Dy'll ions in total. The third protonated alcohol arm, which constitutes the 3-carbon chain, chelates to the Dy"l' site that is bonded to the N-atom. Each of the six $\left(\mathrm{NO}_{3}\right)^{-}$- ions chelate to a single Dy ${ }^{\prime \prime \prime}$ ion, completing the coordination sphere of the ion. The Dy"lI ions are eight coordinate with triangular dodecahedron geometries with the deviations of 2.24 as predicted by SHAPE software. ${ }^{23}$ The average Dy III-O bond length is found to be $2.38 \AA$ A. Selected bond lengths and angles for $\mathbf{4}$ are shown in Table S3.
We note that the metal topology and first coordination sphere is identical to a previous reported $\left\{\mathrm{Dy}_{6}\right\}$ wheel. ${ }^{4 \mathrm{~b}, 4 \mathrm{c}}$ It has been shown that by changing the coordinating atom, bond length and bond angle can have a big effect on the magnetic behaviour of lanthanide complexes. ${ }^{24}$ In previous works we revealed that the $\left\{\mathrm{Dy}_{6}\right\}$ wheel displays a toroidal magnetic moment in the ground state. ${ }^{\mathrm{cb},}, \mathrm{cc}$ Powell and co-workers subsequently reported how ligand field variations affected the toroidal behaviour in two other related $\left\{\mathrm{Dy}_{6}\right\}$ wheels. ${ }^{4 a}$ Due to inclusion of the extra $-\mathrm{CH}_{2}$ - arm we find subtle structural modifications compared to the parent $\left\{\mathrm{Dy}_{6}\right\}$ wheel which we envisage will influence the toroidal and dynamic relaxation behaviour. We find that average Dy...Dy bond length and Dy-O-Dy angles are $3.73 \AA$ and $110.5^{\circ}$, respectively for 4 compared to $3.73 \AA$ and $110.1^{\circ}$ of the parent $\left\{\mathrm{Dy}_{6}\right\}$ wheel. See Table $\mathrm{S} 3$ for a comparison of Dy- $L_{N / O}$ bond lengths, which are significantly different. ${ }^{4 b}$

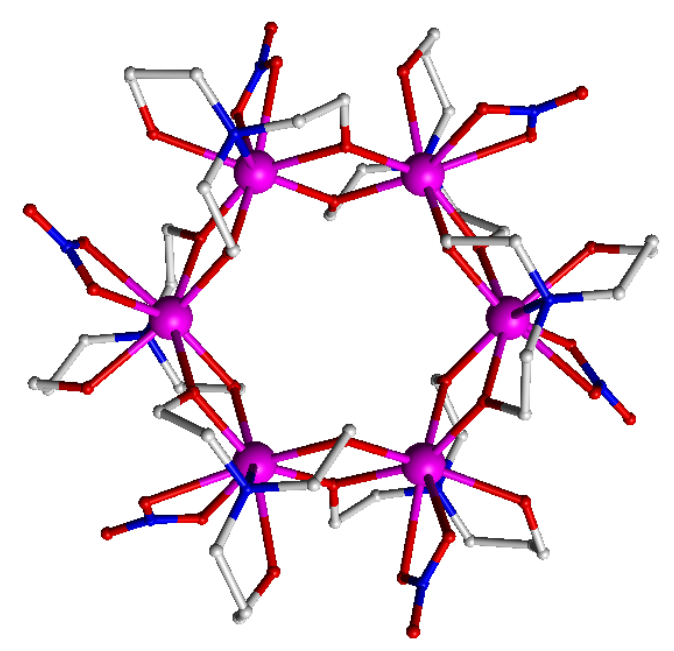

Figure 3. Molecular structure of 4. Colour scheme Dy'II, pink; O, red; $\mathrm{N}$, blue; $\mathrm{C}$, grey, the $\mathrm{H}$-atoms are omitted for clarity.

\section{Magnetic properties}

Magnetic susceptibility data were collected on polycrystalline samples of $\mathbf{1 - 4}$ (under a dc field of $1 \mathrm{~T}$ ) between 2 and $300 \mathrm{~K}$. The data are shown in Figure 4 and are plotted as $\chi_{M} T$ versus $T$. The room temperature values of $35.25,41.63$ and $41.39 \mathrm{~cm}^{3} \mathrm{~K} \mathrm{~mol}^{-1}$ for $\mathbf{1 - 3}$, respectively are in good agreement with the sum of the Curie constants for three non-interacting Tb'II, Dy ${ }^{\prime \prime \prime}$ and Holll ions, respectively of $35.61,42.51$ and $42.21 \mathrm{~cm}^{3} \mathrm{~K} \mathrm{~mol}^{-1}$. As the temperature is decreased the $\chi_{M} T$ product also decreases gradually down to $20 \mathrm{~K}$, before a sharper drop below this temperature reaching values of $8.66,16.72$ and $11.73 \mathrm{~cm}^{3} \mathrm{~K} \mathrm{~mol}^{-1}$ at $2 \mathrm{~K}$. The decrease over the whole temperature range for each complex is due to the depopulation of the crystal field split Stark sublevels of the ground state, with possible weak antiferromagnetic exchange and/or dipolar interactions contributing to the behaviour (see theoretical analysis). The isothermal $M$ versus $H$ plots are shown in Figures 4 and S3-S5. In all cases, the magnetization values do not saturate indicating the presence of anisotropy and/or weak magnetic interactions, with values of magnetization at $5 \mathrm{~T}$ and $2 \mathrm{~K}$ found to be $15.26,17.03$ and 
$19.52 \mathrm{~N} \mu_{\mathrm{B}}$ for $\mathbf{1}-\mathbf{3}$, respectively. Interestingly, for $\mathbf{1}$, we observe an $\mathrm{S}$-shape profile at low magnetic fields $(0-2.5 \mathrm{~T})$ at $2 \mathrm{~K}$ (Figure $\mathrm{S} 4)$, indicating the possible presence of toroidal magnetic behaviour (see theoretical section).
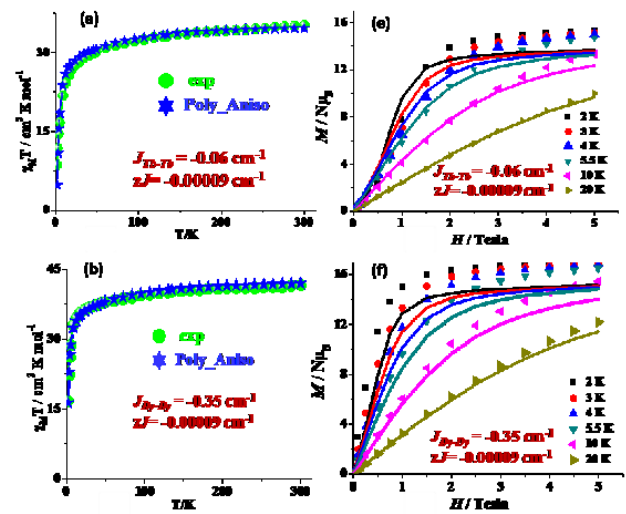

Figure 4 $\chi_{M} T$ vs $T$ lots for a)
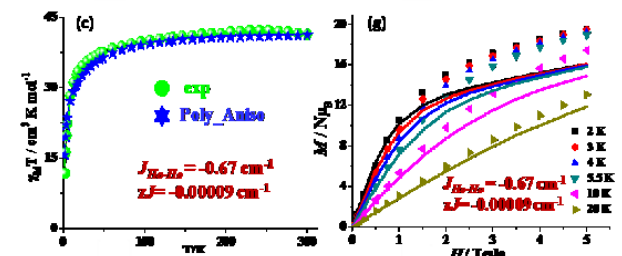

$\left\llcorner\left\{\mathrm{Tb}_{3}\right\}\right.$;

b)

$\left.2\left\{\mathrm{Dy}_{3}\right\} ; \quad \mathrm{c}\right)$

$3\left\{\mathrm{Ho}_{3}\right\}$ and $\mathrm{d}$ )

$4\left\{D_{6}\right\}$ in an applied dc

magnetic
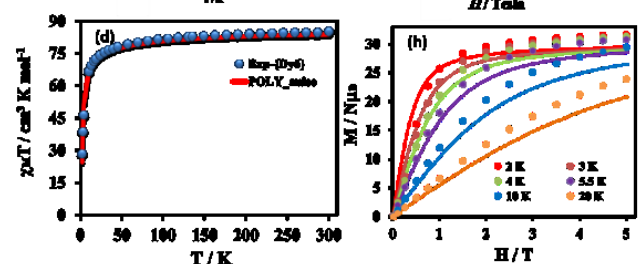

field of $1 \mathrm{~T}$

The

measured

molar

magnetization data for e) $\mathbf{1}\left\{\mathrm{Tb}_{3}\right\}$; f) $\mathbf{2}\left\{\mathrm{Dy}_{3}\right\}$; g) $\mathbf{3}\left\{\mathrm{Ho}_{3}\right\}$ and h) $\mathbf{4}\left\{\mathrm{Dy}_{6}\right\}$. The solid lines are POLY_ANISO fits of the data (see text in the theoretical section). It is noteworthy that, all the $J$ values provided in the graphs correspond to jexch contribution of the total magnetic interaction.

The data for $\mathbf{4}$ are shown in Figure 4 (bottom) and are plotted as $\chi_{M} T$ versus $T$. The room temperature value of $85.23 \mathrm{~cm}^{3} \mathrm{~K} \mathrm{~mol}^{-1}$ is in good agreement with the sum of the Curie constants for six noninteracting Dy III ions of $85.02 \mathrm{~cm}^{3} \mathrm{~K} \mathrm{~mol}^{-1}$. As the temperature is decreased the $\chi_{M} T$ product decreases gradually down to $20 \mathrm{~K}$, before a sharper drop below this temperature, reaching a value of $28.40 \mathrm{~cm}^{3}$ $\mathrm{K} \mathrm{mol}^{-1}$ at $2 \mathrm{~K}$. Again, the decrease over the whole temperature range is due to the depopulation of the crystal field split Stark sublevels of the ground state, with possible weak intramolecular antiferromagnetic exchange and/or dipolar interactions contributing to the behaviour (see theoretical analysis). The isothermal $M$ versus $H$ plots are shown in Figures 4 and S5. Like 1, however to a lesser extent, we observe an S-shape profile at low magnetic fields ( $0-1.5$ $\mathrm{T})$ at $2 \mathrm{~K}$, indicating the possible presence of toroidal magnetic behaviour (see theoretical section).
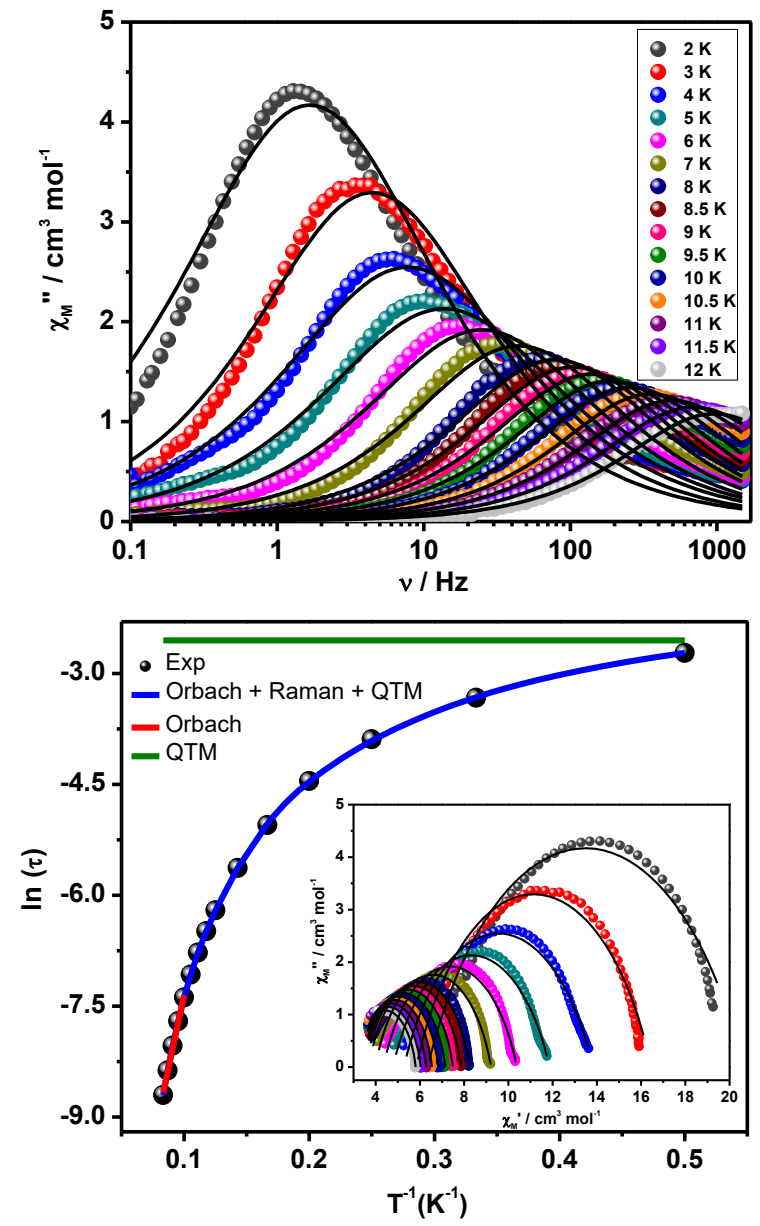

Figure 5. (top) $\chi_{M}$ " vs frequency plots for 4 in an applied dc field $H_{d c}=$ $3000 \mathrm{Oe}$, between $2-12 \mathrm{~K}$. The solid black lines are fitted values obtained from the CC-fit program. ${ }^{25}$ (bottom) Magnetization relaxation time $(\tau)$, plotted as $\ln (\tau)$ versus $T^{-1}$ for 4 . The solid blue line corresponds to fitting of an Orbach relaxation process and the solid red line represents the best fitting to the multiple relaxation process. The horizontal green line represents the QTM relaxation time. (Inset) Cole-Cole plot for 4.

To probe for any slow magnetic relaxation, variable temperature and variable frequency alternating current (ac) susceptibility measurements were performed with an oscillating ac field of $3.5 \mathrm{Oe}$ under a zero applied dc field. No out-of-phase ac susceptibility signals were observed for $\mathbf{1} \mathbf{-} \mathbf{3}$ in zero magnetic field, however out- 
of-phase peaks are observed for 4 between 2 and $4 \mathrm{~K}$ (Figure S6, left). Fitting the data to the Arrhenius law $\left[\tau=\tau_{o} \exp \left(U_{\text {eff }} / k_{B} T\right)\right]$ reveals that for $T=2.2-3.6 \mathrm{~K}$, the plot is linear, yielding an anisotropy barrier $U_{\text {eff }}$ $=14.7(1) \mathrm{K}\left(\sim 10 \mathrm{~cm}^{-1}\right)$, with $\tau_{0}=1.8 \times 10^{-6} \mathrm{~s}$ (Figure S6, right). At the lowest temperature, however, the plot deviates from linearity indicating QTM relaxation is active. To quench the QTM and slow the relaxation times we performed an isothermal $(4 \mathrm{~K})$ magnetic field sweep to find the optimum field with the longest relaxation time at that temperature. This was found to be 3000 Oe (Figure S7). The frequency $(0.1-1500 \mathrm{~Hz})$ and temperature $(2-12 \mathrm{~K})$ dependent outof-phase susceptibilities and Cole-Cole measurements for $\mathbf{4}$ at $H_{d c}=$ 3000 Oe are shown in Figure 5, top. We see that the $\ln (\tau)$ vs $\mathrm{T}^{-1}$ plot is linear between $9.5-12 \mathrm{~K}$, below these temperatures the plot becomes non-linear, indicating a cross over from a thermally activated to a quantum assisted relaxation process.

Fitting the relaxation data using CC-FIT program ${ }^{25}$ extracted the relaxation times with the various relaxation processes (Figure 5, bottom) using the following equation,

$$
1 / \tau=1 / \tau_{\mathrm{QTM}}+C T^{n}+\tau_{o}^{-1} \exp \left(U_{\text {eff }} / k_{B} T\right)
$$

where $1 / \tau_{\text {QTM }}$ corresponds to the relaxation process via QTM pathway, the $C T^{n}$ term corresponds to the relaxation via a Raman process, and the last term accounts for the Orbach relaxation pathway. ${ }^{20 \mathrm{~m}, 24 \mathrm{~d}, 26}$ The values obtained from the best fit are $\mathrm{n}=3.2$, $\mathrm{C}=0.38 \mathrm{~s}^{-1} \mathrm{~K}^{-3.2}, U_{\text {eff }}=81.3 \mathrm{~K}$ and $\tau_{o}=1.1 \times 10^{-7} \mathrm{~s}(\mathrm{R}=0.9994)$ for 4 . A QTM relaxation time, $\tau_{\text {QTM }}$, of $0.08 \mathrm{~s}$ is estimated. The $\mathrm{n}$ value is lower than the expected and this can be attributed to the presence of both optical and acoustic Raman processes involving magnetic relaxation. ${ }^{27}$

\section{Theoretical analysis}

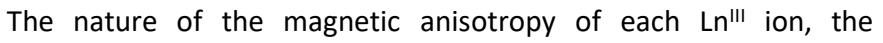
mechanism of single-ion/exchange-coupled magnetic relaxation and the observation/prediction of toroidal behaviour in both the triangular $\left\{\mathrm{Ln}^{\mathrm{III}}\right\}$ ( $\mathrm{Ln}=\mathrm{Tb}(\mathbf{1})$, Dy (2) and $\mathrm{Ho}(\mathbf{3})$ ) and hexagonal wheel $\left\{\right.$ Dy $\left.^{\prime \prime \prime}{ }_{6}\right\}$ (4) systems were analysed using the MOLCAS 8.0 program $^{15}$ harnessing the CASSCF/RASSI-SO/SINGLE_ANISO/POLY_ANISO routine $a b$ initio calculations (See computational details in main manuscript and ESI). We first discuss the relaxation mechanism computed for the single Ln"I ions and then expand this to the exchanged coupled polynuclear complex.

\section{Single ion calculations}

The computed $g$-tensors and the energy values suggest that all $\mathrm{Ln}^{\prime \prime \prime}$ ions are symmetrically equivalent in 1-4. (See Table 1 and Tables S4 - S18 in the ESI). The energy spectrum and $g$-tensors for the Ising doublets of the ground ${ }^{7} \mathrm{~F}_{6}$ multiplet of three $\mathrm{Tb}^{111}$ sites in $\mathbf{1}\left\{\mathrm{Tb}_{3}\right\}$ is given in Tables 1 and S4-S6 in ESI, with subsequent excited state multpilets lying $2120 \mathrm{~cm}^{-1}$ above the ground multiplet. The ground and excited pseudo-doublets exhibit pure Ising type anisotropy for all the symmetrically equivalent magnetic sites. The $g_{z}$ parameter of the ground pseudo-doublet state (see Figure 6a, yellow dashed lines for the orientation of the ground state anisotropy axis) is close to that expected for a pure $m_{J}= \pm 6$ states (see Tables S4-S6). In all the equivalent sites, a substantial $\Delta_{\text {tun }}\left(>10^{-5} \mathrm{~cm}^{-1}\right)$ within the ground pseudo-doublets was detected $\left(\sim 0.2 \mathrm{~cm}^{-1}\right)$. To understand the orign of such spilitting, crystal field analysis were performed which indicate predominantly large axial terms (see Table S7), however, the competitive nature of the non-axial terms suppresses the dominant axiality. Therefore, both the prevalent non-axial crystal field parameters in conjunction with a large tunnel splitting within ground pseudo-doublets preclude any SMM characteristics, due to quantum tunnelling relaxation mechanism originating in the ground state. This analysis is complemented experimentally by the lack of out-of-phase susceptibility signals from the ac measurements. The energy spectrum and $g$-tensors for the Kramers doublets of the ground ${ }^{6} \mathrm{H}_{15 / 2}$ multiplet of the three Dy'l' sites in $\mathbf{2}\left\{\mathrm{Dy}_{3}\right\}$ complex, are shown in Tables 1 and S8-S10, with subsequent excited multiplet states lying $\sim 3090 \mathrm{~cm}^{-1}$ above the ground muliplet. The ground state (GS) Kramers doublet shows an axial type anisotropy for all the three metal centres (see Table 1 and S8-S10) i.e. $g_{z z}$ (see Figure 6b, yellow dashed lines for the orientation of the main anisotropy axis for the ground KD in all three Dy ${ }^{\text {III }}$ sites) is close to that expected for a pure $m_{J}= \pm 15 / 2$ state $\left(g_{x}=0.06, g_{y}=0.11, g_{z}=19.66\right)$. For each Dy $y^{\prime \prime \prime}$ ion, the angle between $g_{z}$ directions of the ground and first excited KD is estimated to be $\sim 104^{\circ}$. It indicates that the magnetic relaxation to be operative via the first excited KD in all three equivalent Dy"ll centres. Therefore, based on single-ion analysis, the computed energy barrier for magnetization reversal $\left(U_{\text {cal }}\right)$ can be enumerated as $112 \mathrm{~cm}^{-1}$ for all the three symmetrically equivalent Dy"ll centres. This therefore suggests SMM behaviour is possible for complex 2 . However, the presence of large non-axial crystal field parameters (See Table S11) indicate prominent QTM effects in ground state which can lead to lack of SMM behaviour in $\mathbf{2}$. This accords well with the experimental observation of an absence of a frequency dependent out-of-phase magnetic susceptibility signal (zero field). The energy spectrum and $g$-tensors for the Ising doublets of the ground ${ }^{5} I_{8}$ multiplet of the three $\mathrm{Ho}^{\text {III }}$ sites in $\mathbf{3}\left\{\mathrm{Ho}_{3}\right\}$ are shown in Tables 1 and S12-S14, with subsequent excited multiplet states lying $\sim 5275 \mathrm{~cm}^{-1}$ above the ground multiplet. The ground and excited state pseudo-doublets exhibit pure Ising type anisotropy for all three equivalent Holl' sites owing to the overall non-Kramers nature of the Holl' centres. The ground state $g_{z}$ value (see Figure $6 c$, yellow dashed lines for the orientation of main anisotropy axis for the ground pseudo-doublet for all three Holl' sites) is close to that expected for a pure $m_{J}= \pm 8$ state (see Tables 1 and S12-14). Based on the single-ion analysis, a pronounced $\Delta_{\text {tun }}$ was computed within the ground pseudo-doublets ( $\sim \mathrm{cm}^{-1}$ i.e. > cut-off of $\left.10^{-5} \mathrm{~cm}^{-1}\right)$ for all Holll sites. This restricts the observation of SMM behaviour in 3. Substantial non-axial crystal field parameters (See Table S15) further corroborated the lack of SMM behaviour in $\mathbf{3}$ from experiment.

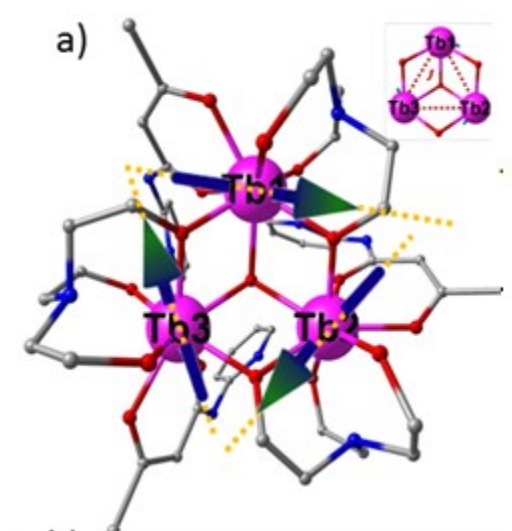


indicating under barrier relaxation pathways are operational even in the presence of a static $d c$ field.
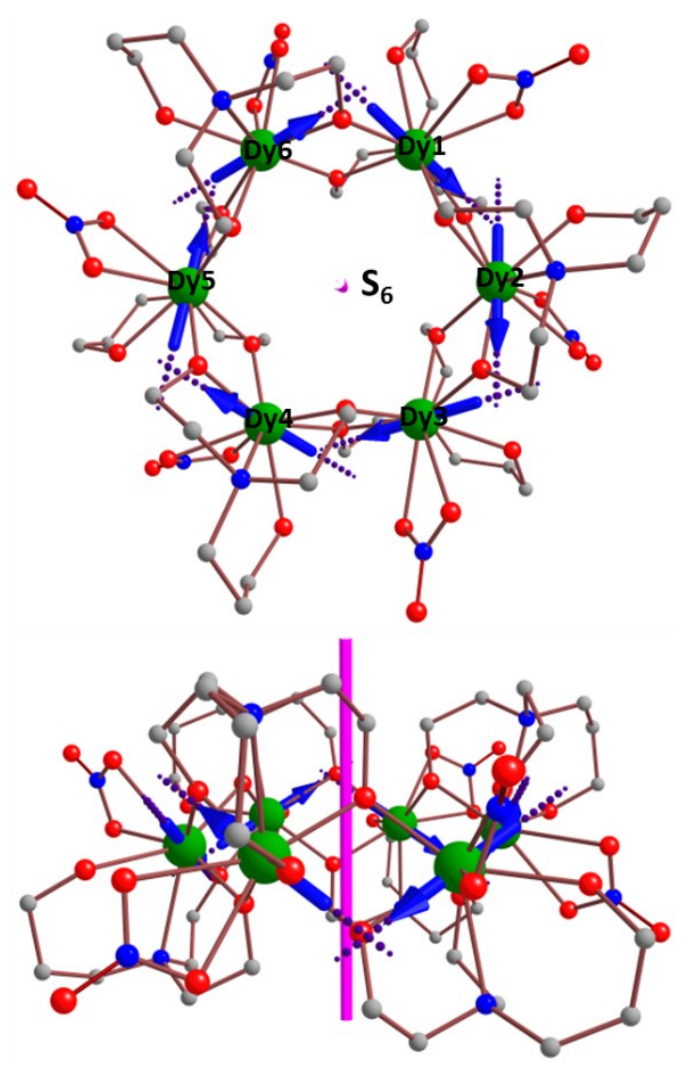

Figure 6. The directions of the local anisotropy axes in the ground doublets on the Ln'II sites (yellow dashed lines) and of the local magnetic moments (colour arrows) in the ground exchange doublet of a) $\mathbf{1}\left\{\mathrm{Tb}_{3}\right\}$; b) $\mathbf{2}\left\{\mathrm{Dy}_{3}\right\}$; c) $\mathbf{3}\left\{\mathrm{Ho}_{3}\right\}$.

The local $g$-tensors of each Dy'II ion in the ground Kramers doublet of 4 (Dy'I' 6 ) are strongly axial in nature (Tables 1 and S16) indicating the possibility of slow magnetic relaxation originating from the single ion. The orientations of the main anisotropy axes in the ground KDs of $\mathbf{4}$ is shown in Figure 7, top and middle.

The computed energy gap between the ground KDs and the excited states for $\mathbf{4}$ are shown in Tables 1 and S18. In complex $\mathbf{4}$, the energy gap between the ground and the first excited KD is calculated to be $\sim 108 \mathrm{~cm}^{-1}$ for all the Dy ${ }^{\prime \prime \prime}$ ions. A qualitative mechanism for the single ion magnetic relaxation for Dy1 is shown in Figure 7, bottom and a similar kind of mechanism is observed for other Dy"lI ions. The ground-state tunnelling probability (QTM) is small, becoming larger in the first excited states for all Dy'll ions, therefore single-ion magnetic relaxation can occur via first excited states involving thermally assisted QTM. The computed barrier can be compared with the experimental out-of-phase ac measurements at a static dc field of 3000 Oe $\left(U_{\text {eff }}=81.3 \mathrm{~K}\right)$, which is slightly less than calculated

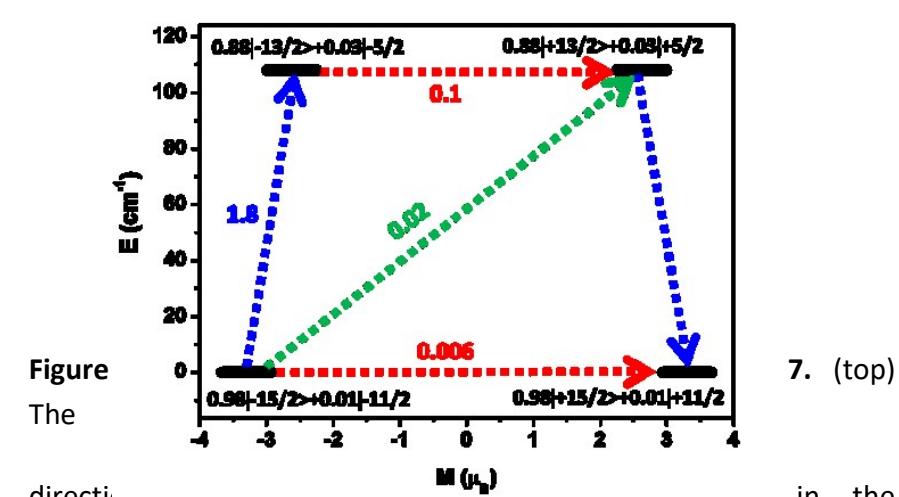

directiv... $u$, ,... ,ur. in the ground doublets on the Ln"l' sites (violet dashed lines) and of the local magnetic moments (blue arrows) in the ground exchange doublet of $4\left\{\mathrm{Dy}_{6}\right\}$. The $\mathrm{S}_{6}$ axis is shown as a pink bold line. (middle) side view of 4\{Dy $\left.{ }_{6}\right\}$. (bottom) The $a b$ initio computed magnetization blocking barrier for the Dy 1 site in $\mathbf{4}\left\{\mathrm{Dy}_{6}\right\}$. The thick black line indicates the Kramer's doublets as a function of computed magnetic moment. The green/blue arrows show the possible pathway through Orbach/Raman relaxation. The dotted red lines represent the presence of QTM/TA-QTM between the connecting pairs. The numbers provided at each arrow are the mean absolute value for the corresponding matrix element of transition magnetic moment. 
Table 1. Low-lying energies $\left(\mathrm{cm}^{-1}\right)$ and $g$-tensors of $\operatorname{Ln} 1$ fragments of 1-4 that originate from the corresponding ground atomic multiplets.

\begin{tabular}{|l|l|l|l|l|}
\hline & $\mathbf{1}\left\{\mathrm{Tb}_{3}\right\}$ & $\mathbf{2}\left\{\mathrm{Dy}_{3}\right\}$ & $\mathbf{3}\left\{\mathrm{Ho}_{3}\right\}$ & $\mathbf{4}\{\mathrm{Dy}\}$ \\
\hline & 0.0 & 0.00 & 0.0 & 0.0 \\
& 0.18 & 112.1 & 2.8 & 108.1 \\
& 166.6 & 169.1 & 20.5 & 221.3 \\
& 179.3 & 250.8 & 26.6 & 281.5 \\
& 199.1 & 315.1 & 70.3 & 338.2 \\
& 225.1 & 356.6 & 76.2 & 444.9 \\
& 281.0 & 446.3 & 117.3 & 562.9 \\
& 325.6 & 554.7 & 128.4 & 680.9 \\
& 342.8 & & 150.9 & \\
& 437.5 & & 183.3 & \\
& 442.4 & & 202.5 & \\
& 513.0 & & 216.8 & \\
& 515.1 & & 222.8 & \\
\hline$g_{x x}$ & 0.0000 & 0.0600 & 0.0000 & 0.0134 \\
$g_{y y}$ & 0.0000 & 0.1100 & 0.0000 & 0.0213 \\
$g_{z z}$ & 17.8100 & 19.6600 & 17.1300 & 19.8178 \\
\hline
\end{tabular}

\section{Exchange-coupled Magnetic Relaxation and Toroidal Behaviour}

The magnetic exchange and dipolar interactions between nearestneighbour L $\mathrm{n}^{\text {III }}$ sites of 1-4 were simulated using the POLY_ANISO program ${ }^{22}$ and the values are listed in Table 2. By considering the exchange constants $\left(J_{\text {exch }}+J_{\text {dip }}\right)$ values, good fits to both the susceptibility and the magnetization data were attained for both triangular and wheel systems (Figure 4).

Table 2. POLY_ANISO ${ }^{22}$ fitted exchange and dipolar couplings $\left(\mathrm{cm}^{-1}\right)$

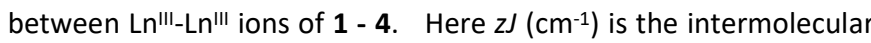
exchange interaction.

\begin{tabular}{|c|c|c|c|c|}
\hline Complex & $J_{\text {exch }}$ & $J_{\text {dip }}$ & $J_{\text {tot }}$ & $z J$ \\
\hline $\mathbf{1}$ & -0.06 & -0.19 & -0.25 & -0.00009 \\
\hline $\mathbf{2}$ & -0.35 & +0.07 & -0.28 & -0.00009 \\
\hline $\mathbf{3}$ & -0.67 & +0.11 & -0.56 & -0.00009 \\
\hline $\mathbf{4}$ & -0.10 & +1.10 & +1.00 & -0.01 \\
\hline
\end{tabular}

Pure Ising type pseudo-doublets associated with all the Tb"II centres in $\mathbf{1}$ is indicative of the possibility of an Ising type magnetic interaction between the Tb"I centres. We have simulated the magnetic exchange coupling between the Tb'"I ions, including the magnetic dipole-dipole, as well as the exchange interaction contributions within the Ising exchange Hamiltonian, harnessing the POLY_ANISO suite. Experimental magnetic data $\left(\chi_{\mathrm{M}} T(T)\right.$ and $\left.M(H)\right)$ was reproduced nicely through our simulations with the parameters $J=-0.06 \mathrm{~cm}^{-1}$ at intermolecular interaction $(\mathrm{zJ})=-0.00009 \mathrm{~cm}^{-1}$ (see Figure 4 and Table 2).

Taking into account the Ising type exchange interaction, the following Hamiltonian becomes applicable:
$\widetilde{H_{e x}}=-\sum_{i=1}^{3} \widetilde{J_{l}} \tilde{S}_{i z} \tilde{S}_{i+1 z} ;$ where $\tilde{S}_{i z}$ implies pseudo-spin projection on the anisotropy axis of $\mathrm{i}^{\text {th }}$ centre and also illustrates two states with reversed maximal magnetization on this magnetic site. Concepts based on the Lines model and the above Hamiltonian has aided derivation of equation: $\tilde{J}_{i}=25 \cos \phi_{\mathrm{i}, \mathrm{j}+1} J_{\mathrm{i}}$. Here, $\phi_{\mathrm{i}, \mathrm{j}+1}$ corresponds to angle between the anisotropy axes on the centres I and $\mathrm{i}+1$. As $\phi_{\mathrm{i}, \mathrm{j}+1}$ $\sim 2 \pi / 3, \tilde{J}_{i}=-12.5 J_{\mathrm{i}}$. This approximation resulted in ferromagnetic $\tilde{J}$ between Tb"II centres for antiferromagnetic $J$, as observed in 1 (See Table 2). This renders a ferromagnetic alignment of the pseudospins (bluish-green arrows in Figure 6a) which is collinear with the direction of the main anisotropy axis (dashed yellow lines in Figure 6a). Moreover, the local magnetization vectors are almost found to lie in the $\left\{\mathrm{Tb}_{3}\right\}$ plane with an out-of-plane angle in the range of $2^{\circ}$ (See Table S17). Besides, they are almost tangential to the vertices of the $\left\{\mathrm{Tb}^{\prime \prime \prime}{ }_{3}\right\}$ triangle, which exemplifies 1 as a complex exhibiting an almost perfect toroidal magnetic moment (see Figure 6a). Next, we attempt to analyse the overall non-Kramers type exchange coupled system in 1 i.e. overall $\left|M_{J}\right\rangle=6 * 3=18$ states. Due to the nonKramers nature of the $\mathrm{Tb}^{\prime \prime I}$ ion, all the exchange pseudo-doublets possess almost negligible matrix elements of the transversal magnetic moment $\left(\sim 10^{-5}-10^{-9} \mu_{\mathrm{B}}\right)$ pertinent to QTM/TA-QTM processes but differ significantly in terms of tunnel splitting (see Table 3). A prominent $\Delta_{\text {tun }}$ of $\sim 10^{-4} \mathrm{~cm}^{-1}$ (higher than the cut-off of $\sim 10^{-5} \mathrm{~cm}^{-1}$ ) was detected within the ground pseudo exchange doublet in 1 . This results in fast relaxation of magnetization through ground exchange state itself (see Figure 8a) negating any SMM behaviour. Despite three symmetrically equivalent Tb"II sites, the magnetic moments of the Tb"II ions do not compensate completely. Rather, they sum up to a total momentum of $\mu_{2}=$ $1 / 2 g_{2} \mu_{B}=0.87 \mu_{B}$ in the ground exchange pseudo-doublet, which is much smaller than the magnetic moment on each $\mathrm{Tb}^{\text {III }}$ site in the ground state i.e. $9 \mu_{B}$. From Figure $4 a$, the $\chi_{M} T$ value diminishes at low temperature (both poly_aniso fit and experimental data) denoting a non-magnetic ground state. However, the non-collinear exchange between localized magnetic moments does not compensate each other completely resulting in small residual ground pseudo exchange doublet magnetic moment. This accords well with the non-zero magnitude of magnetization even at low temperature as evident from Figure $4 \mathrm{e}$ and is reminiscent of earlier reports on $\mathrm{Dy}_{3}$ triangles $^{2 \mathrm{a}}$, 201,28 . Therefore, we can conclude that, complex $\mathbf{1}$ is not a SMM but shows mixed moment type SMT behaviour. 


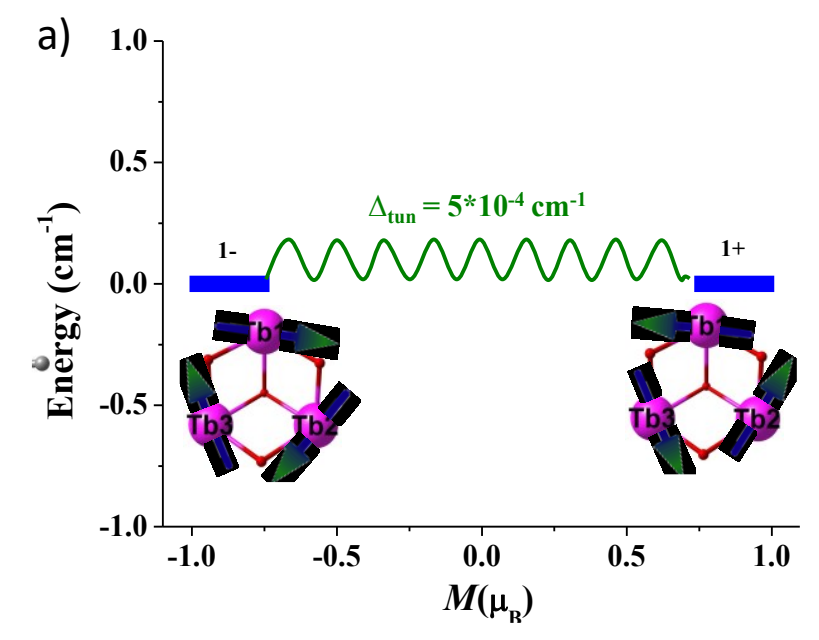

Table 3. Energies $\left(\mathrm{cm}^{-1}\right)$, corresponding tunnel splitting $\left(\Delta_{\text {tun }}\right)$ and $\mathrm{g}_{2}$ values of the low-lying exchange doublet state in complex $\mathbf{1}$ :

\begin{tabular}{|c|c|c|c|c|}
\hline Multiplets & $\begin{array}{l}\text { Energy } \\
\left(\mathrm{cm}^{-1}\right)\end{array}$ & \multicolumn{2}{|c|}{$\begin{array}{l}\text { Main values of } \\
\mathrm{g} \text { tensor }\end{array}$} & $\begin{array}{l}\Delta_{\text {tun }} \\
\left(\mathrm{cm}^{-1}\right)\end{array}$ \\
\hline \multirow[t]{3}{*}{1} & \multirow{3}{*}{$\begin{array}{l}0.0000 \\
0.0000\end{array}$} & $g_{x x}$ & $1 * 10^{-9}$ & \multirow[t]{3}{*}{0.0005} \\
\hline & & $\mathrm{g}_{y y}$ & $2 * 10^{-9}$ & \\
\hline & & $\mathrm{g}_{z z}$ & 1.74 & \\
\hline \multirow[t]{3}{*}{2} & \multirow{3}{*}{$\begin{array}{l}3.841 \\
3.920\end{array}$} & $\overline{g x x}$ & $3 * 10^{-7}$ & \multirow[t]{3}{*}{0.0788} \\
\hline & & $\mathrm{g}_{\mathrm{yy}}$ & $2 * 10^{-5}$ & \\
\hline & & $\mathrm{g}_{\mathrm{zz}}$ & 25.26 & \\
\hline \multirow[t]{3}{*}{3} & 3.925 & $g_{x x}$ & $2 * 10^{-7}$ & \multirow[t]{3}{*}{0.1696} \\
\hline & \multirow[t]{2}{*}{4.094} & $\mathrm{~g}_{\mathrm{yy}}$ & $9 * 10^{-6}$ & \\
\hline & & $g_{z z}$ & 17.95 & \\
\hline \multirow[t]{3}{*}{4} & \multirow{3}{*}{$\begin{array}{l}4.099 \\
4.189\end{array}$} & $g_{x x}$ & $4 * 10^{-7}$ & \multirow[t]{3}{*}{0.0903} \\
\hline & & $\mathrm{g}_{\mathrm{yy}}$ & $2 * 10^{-5}$ & \\
\hline & & $\mathrm{g}_{\mathrm{zz}}$ & 25.25 & \\
\hline \multirow[t]{3}{*}{5} & 168.311 & $g_{x x}$ & $9 * 10^{-8}$ & \multirow[t]{3}{*}{0.0135} \\
\hline & \multirow[t]{2}{*}{168.325} & $\mathrm{~g}_{\mathrm{yy}}$ & $2 * 10^{-6}$ & \\
\hline & & $g_{z z}$ & 8.266 & \\
\hline
\end{tabular}
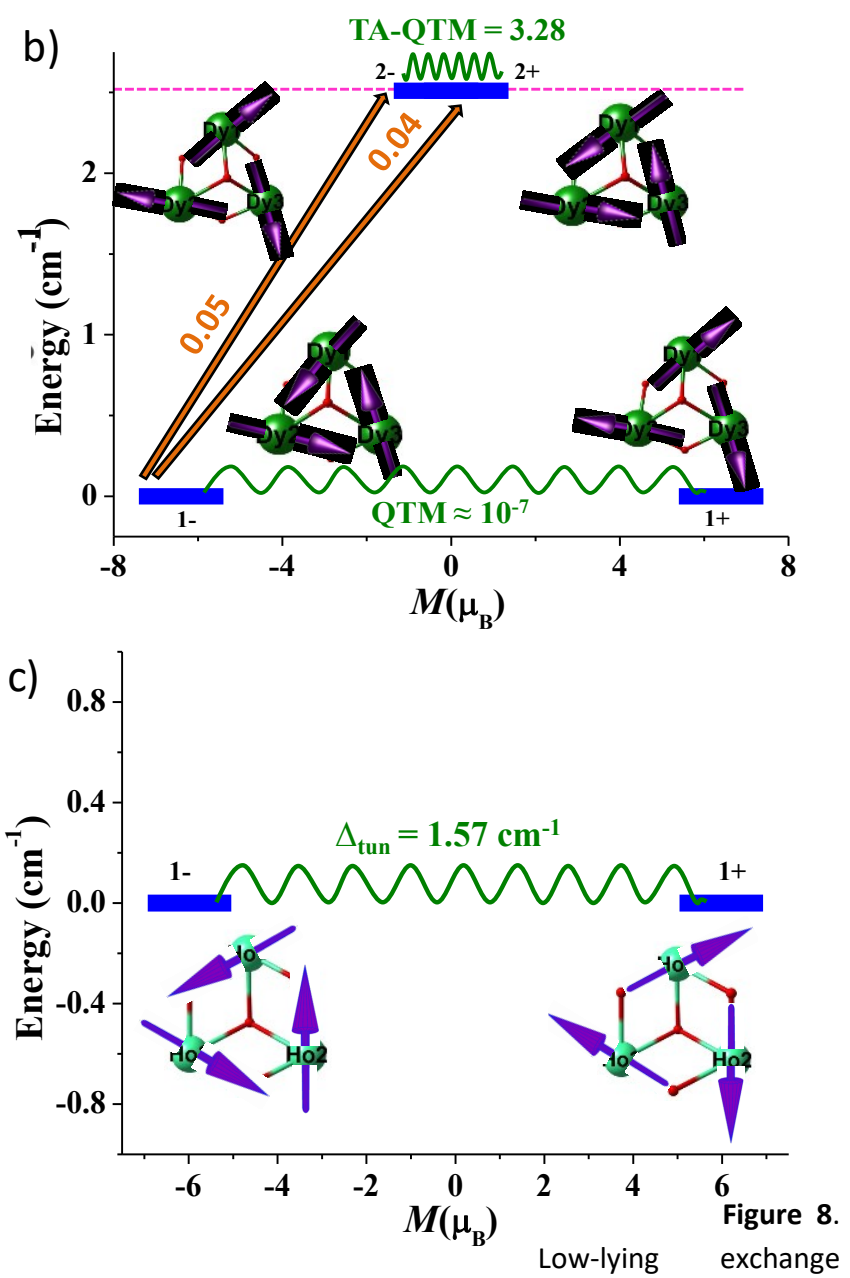

spectrum in complex a) $\mathbf{1}\left\{\mathrm{Tb}_{3}\right\}$; b) $\mathbf{2}\left\{\mathrm{Dy}_{3}\right\}$; c) $\mathbf{3}\left\{\mathrm{Ho}_{3}\right\}$. Every exchange state (represented by thick blue lines) has been arranged based on the corresponding magnetic moment. The curved green arrows interpret tunnelling transition ( $\Delta_{\text {tun; }}$ tunnel splitting or tunnel gaps) within each doublet. At few energy levels the corresponding noncollinear Ising quantum states with thick arrows at the $\mathrm{Ln}^{\text {III }}$ sites indicate magnetic moment direction in toroidal form.

Table 4. Energies $\left(\mathrm{cm}^{-1}\right)$, corresponding tunnel splitting $\left(\Delta_{\mathrm{tun}}\right)$ and $\mathrm{g}_{z}$ values of the low-lying exchange doublet state in complex $\mathbf{2}$ :

\begin{tabular}{|c|c|c|c|c|}
\hline Multiplets & $\begin{array}{l}\text { Energy } \\
\left(\mathrm{cm}^{-1}\right)\end{array}$ & \multicolumn{2}{|c|}{$\begin{array}{l}\text { Main values } \\
\text { of } g \text { tensor }\end{array}$} & $\begin{array}{l}\Delta_{\text {tun }} \\
\left(\mathrm{cm}^{-1}\right)\end{array}$ \\
\hline \multirow[t]{3}{*}{1} & \multirow{3}{*}{$\begin{array}{l}0.0000 \\
0.0000\end{array}$} & $g_{x x}$ & $1 * 10^{-7}$ & \multirow[t]{3}{*}{$1 * 10^{-10}$} \\
\hline & & $\mathrm{g}_{\mathrm{yy}}$ & $4 * 10^{-7}$ & \\
\hline & & $g_{z z}$ & 12.80 & \\
\hline \multirow[t]{3}{*}{2} & \multirow{3}{*}{$\begin{array}{l}2.506 \\
2.506\end{array}$} & $\overline{g x x}$ & 24.56 & \multirow[t]{3}{*}{$1 * 10^{-1 C}$} \\
\hline & & $\mathrm{g}_{\mathrm{yy}}$ & 13.41 & \\
\hline & & $g_{z z}$ & 0.06 & \\
\hline \multirow[t]{3}{*}{3} & \multirow{3}{*}{$\begin{array}{l}2.535 \\
2.535\end{array}$} & $g_{x x}$ & 0.02 & \multirow[t]{3}{*}{$3 * 10^{-11}$} \\
\hline & & $\mathrm{g}_{\mathrm{yy}}$ & 3.91 & \\
\hline & & $g_{z z}$ & 11.78 & \\
\hline \multirow[t]{3}{*}{4} & \multirow{3}{*}{$\begin{array}{l}2.563 \\
2.563\end{array}$} & $g_{x x}$ & 25.42 & \multirow[t]{3}{*}{$1 * 10^{-10}$} \\
\hline & & $\mathrm{g}_{\mathrm{yy}}$ & 12.87 & \\
\hline & & $g_{z z}$ & 0.06 & \\
\hline \multirow[t]{3}{*}{5} & \multirow{3}{*}{$\begin{array}{l}109.686 \\
109.686\end{array}$} & $g_{x x}$ & $6 * 10^{-5}$ & \multirow[t]{3}{*}{$1 * 10^{-9}$} \\
\hline & & $\mathrm{g}_{\mathrm{yy}}$ & $1 * 10^{-4}$ & \\
\hline & & $g_{z z}$ & 22.62 & \\
\hline
\end{tabular}

Similar to the earlier explanation, a nice agreement between experimental and POLY_ANISO simulated magnetic data (see Figure $4 \mathrm{~b}$ and $4 \mathrm{f}$ ) was established with $J=-0.35 \mathrm{~cm}^{-1}$ at $\mathrm{zJ}=-0.00009 \mathrm{~cm}^{-1}$ in complex 2 (See Table 2). This approximation leads to ferromagnetic $\tilde{J}$ between Dy $y^{\prime \prime \prime}$ centres for antiferromagnetic J (See Table 2). This leads to the ferromagnetic alignment of the pseudospins (purple arrows in Figure $6 \mathrm{~b}$ ) which is collinear with the direction of the main anisotropy 
axis (yellow dashed lines in Figure 6b). Moreover, the local magnetization vectors are found to lie close to the $\left\{\right.$ Dy $\left.^{\prime \prime \prime}{ }_{3}\right\}$ plane, with an out-of-plane angle in the range of $13^{\circ}$ (see Table S17). Besides, they are almost tangential to the vertices of the $\left\{\mathrm{Dy}^{\prime \prime \prime}{ }_{3}\right\}$ triangle which reveals complex $\mathbf{2}$ exhibits a toroidal magnetic moment (see Figure $6 b)$. Next, we analyse the Kramers type exchange system for 2 i.e. overall $\left|M_{J}\right\rangle=15 / 2 * 3=45 / 2$ states. Due to the Kramers nature of the Dy'll ion, all the exchange Kramers doublets possess almost negligible matrix tunnel splitting between them $\left(\sim 10^{-9}-10^{-11} \mathrm{~cm}^{-1}\right.$; see Table 4). Since the exchange-coupled $\left|M_{J}\right\rangle$ states are Kramers in nature, the matrix elements of the transversal magnetic moment (QTM/TA-QTM values) tend to dominate in predicting magnetic relaxation. The matrix element pertaining to the ground state QTM is negligible (less than the cut-off value of $10^{-3} \mu_{\mathrm{B}}$; see Figure $8 \mathrm{~b}$ and Table 4). However, a substantial amount of matrix element corresponding to operative TA-QTM within the first excited exchange doublet ( $3.28 \mu_{\mathrm{B}}$; see Figure $8 \mathrm{~b}$ and Table 4 ) promotes relaxation via the first excited exchange doublet. This implies the computed energy barrier as $2.5 \mathrm{~cm}^{-1}$ for complex 2 supporting the observed absence of frequency dependent out-of-phase magnetic susceptibility (zerofield or in presence of field). Hence, the weak antiferromagnetic exchange interaction between Dy III sites dominate enough to quench the QTM at the ground state at the single-ion level leading to possible relaxation in the polynuclear framework. However, due to the small barrier in the exchange coupled famework slow relaxation is not expected to be observed in line with the experimental magnetic data. Despite the three equivalent Dy'll sites, the magnetic moments of the Dy III ions do not compensate completely. Rather, they sum up to a total momentum of $\mu_{2}=1 / 2 g_{2} \mu_{B}=6.40 \mu_{B}$ in the ground exchange pseudo-doublet, which is much smaller than the magnetic moment on each Dy'II site in the ground state, i.e. $10 \mu_{\mathrm{B}}$. From Figure $4 \mathrm{~b}$, the $\chi_{M} T$ value diminishes at low temperature, but to a lesser extent than 1. Non-collinear exchange between localized magnetic moments does not compensate each other resulting in a small residual ground pseudo exchange doublet magnetic moment (larger than 1). This accords well with the non-zero magnetization value even at low temperature as evident from Figure $4 \mathrm{f}$ and is reminiscent of earlier reports on $\left\{\mathrm{Dy}_{3}\right\}$ triangles. ${ }^{2 \mathrm{a}} 201,28$ Therefore, we can conclude that complex 2 is not an SMM, but shows mixed moment type SMT behaviour.

The POLY_ANISO simulation for 3 revealed $J=-0.67 \mathrm{~cm}^{-1}$ with an intermolecular interaction $(\mathrm{z} J)=-0.00009 \mathrm{~cm}^{-1}$ (see Figures $4 \mathrm{c}, 4 \mathrm{~g}$ and Table 2). This is similar to the outcomes calculated from the $\mathbf{1}\left\{\mathrm{Tb}_{3}\right\}$ and $\mathbf{2}\left\{\mathrm{Dy}_{3}\right\}$ triangles and with a ferromagnetic alignment of the local magnetization vectors on the three $\mathrm{Ho}^{\text {III }}$ centres. The spins form an $18-20^{\circ}$ angle with the $\left\{\mathrm{Ho}_{3}\right\}$ plane and almost tangential orientation of these local magnetization vectors induce SMT behaviour in $\mathbf{3}$. Next, we have explored the non-Kramers type exchange coupled system in 3 i.e. overall $\left|M_{J}\right\rangle=8 * 3=24$ states. All the exchange pseudo-doublets possess negligible matrix elements of the transversal magnetic moment $\left(\sim 10^{-6}-10^{-9} \mu_{B}\right)$ corresponding to QTM/TA-QTM but differ significantly in terms of tunnel splitting (see Table 5). A prominent $\Delta_{\text {tun }}=1.57 \mathrm{~cm}^{-1}$ (higher than the cut-off of $\sim 10$ ${ }^{5} \mathrm{~cm}^{-1}$ ) was detected within the ground pseudo exchange doublet.
This results in fast relaxation of magnetization through the ground exchange state (see Figure $8 \mathrm{~b}$ ), precluding any SMM behaviour. Despite three symmetrically equivalent $\mathrm{Ho}^{\prime \prime \prime}$ sites, the magnetic moments of the Ho'll ions in $\mathbf{3}$ do not compensate completely. Rather, they sum up to a total momentum of $\mu_{z}=1 / 2 g_{2} \mu_{B}=5.98 \mu_{B}$ in the ground exchange pseudo-doublet which is much smaller than the magnetic moment on each Holl' site in the ground states i.e. $9 \mu_{\mathrm{B}}$. From Figure $4 c$, the $\chi_{M} T$ value diminishes at low temperature but less so than in $\mathbf{1}$ and similar to the behaviour in $\mathbf{2}$. Non-collinear exchange between localized magnetic moments does not compensate each other resulting in small residual ground pseudo exchange doublet magnetic moment (larger than 1). This accords well with the nonzero magnitude of magnetization even at low temperature as evident from Figure $4 \mathrm{~g}$ and is reminiscent of earlier reports on $\left\{\mathrm{Dy}_{3}\right\}$ triangles. ${ }^{2 a}, 201,28$ Therefore, we can conclude that, complex $\mathbf{3}$ is not SMM but shows mixed moment type SMT behaviour.

Table 5. Energies $\left(\mathrm{cm}^{-1}\right)$, corresponding tunnel splitting $\left(\Delta_{\mathrm{tun}}\right)$ and $\mathrm{g}_{z}$ values of the low-lying exchange doublet state in complex $\mathbf{3}$ :

\begin{tabular}{|c|c|c|c|c|}
\hline Multiplets & $\begin{array}{l}\text { Energy } \\
\left(\mathrm{cm}^{-1}\right)\end{array}$ & \multicolumn{2}{|c|}{$\begin{array}{l}\text { Main values } \\
\text { of } g \text { tensor }\end{array}$} & $\begin{array}{l}\Delta_{\text {tun }} \\
\left(\mathrm{cm}^{-1}\right)\end{array}$ \\
\hline \multirow[t]{3}{*}{1} & \multirow{3}{*}{$\begin{array}{l}0.000 \\
1.573\end{array}$} & $g_{x x}$ & $1 * 10^{-7}$ & \multirow[t]{3}{*}{1.573} \\
\hline & & $g_{y y}$ & $4 * 10^{-7}$ & \\
\hline & & $g_{z z}$ & 12.80 & \\
\hline \multirow[t]{3}{*}{2} & \multirow{3}{*}{$\begin{array}{l}3.706 \\
4.056\end{array}$} & $g_{x x}$ & $6 * 10^{-7}$ & \multirow[t]{3}{*}{0.350} \\
\hline & & $g_{y y}$ & $2 * 10^{-6}$ & \\
\hline & & $g_{z z}$ & 0.29 & \\
\hline \multirow[t]{3}{*}{3} & \multirow{3}{*}{$\begin{array}{l}4.937 \\
6.593\end{array}$} & $g_{x x}$ & $2 * 10^{-7}$ & \multirow[t]{3}{*}{1.656} \\
\hline & & $\mathrm{g}_{\mathrm{yy}}$ & $1 * 10^{-6}$ & \\
\hline & & $g_{z z}$ & 0.13 & \\
\hline \multirow[t]{3}{*}{4} & \multirow{3}{*}{$\begin{array}{l}7.000 \\
9.195\end{array}$} & $g_{x x}$ & $3 * 10^{-8}$ & \multirow[t]{3}{*}{2.195} \\
\hline & & $g_{y y}$ & $9 * 10^{-7}$ & \\
\hline & & $g_{z z}$ & 21.48 & \\
\hline \multirow[t]{3}{*}{5} & 18.692 & $g_{x x}$ & $5 * 10^{-8}$ & \multirow[t]{3}{*}{0.309} \\
\hline & \multirow[t]{2}{*}{19.001} & $g_{y y}$ & $2 * 10^{-7}$ & \\
\hline & & $g_{z z}$ & 0.22 & \\
\hline
\end{tabular}

Hence, our theoretical analysis on complexes 1-3 leads to the following summary (Table 6):

Table 6. Summary of results of $\mathbf{1} \mathbf{-} \mathbf{3}$ from ab initio calculations.

\begin{tabular}{|c|c|c|c|c|}
\hline Complexes & SMM & \multicolumn{3}{|c|}{ SMT } \\
\hline & & Type & $\mathrm{T}_{\mathrm{z}}$ & $\mathrm{M} / \mu_{\mathrm{B}}$ \\
\hline $\mathbf{1}$ & No & Yes, Mixed moment & $\neq 0$ & 0.87 \\
\hline $\mathbf{2}$ & No & Yes, Mixed moment & $\neq 0$ & 6.40 \\
\hline $\mathbf{3}$ & No & Yes, Mixed moment & $\neq 0$ & 5.98 \\
\hline
\end{tabular}

Analysis of the exchange coupling for $\mathbf{4}$ reveals that the tilt angle $(\theta)$ between the orientation of the magnetic moments and the vector connecting two Dy III centres is found to be $\sim 38^{\circ}$ which is lower than $54.75^{\circ}$ which can decide the nature of dipolar interaction. ${ }^{29}$ This 
lesser angle causes a ferromagnetic dipolar contribution to the net magnetic exchange.

In 4, the tunnelling gap of the ground exchange coupled states is small becoming larger at the first and second excited states (Figure 9). Furthermore, Table S19 shows that those coupled excited states are very close in energy resulting in fast relaxation of magnetization via second excited states at $4.2 \mathrm{~cm}^{-1}$. This lies in line with the small observed anisotropy barrier $\left(\sim 10 \mathrm{~cm}^{-1}\right)$ as determined experimental out-of-phase ac magnetic susceptibilities in a zero static dc field.

The direction of the local anisotropy axes on all Dy"ll sites are shown in Figure 7 (top and middle), by dashed lines. The angle of these axes with the main symmetry axis of the $4\left\{D_{6}\right\}$ complex $\left(S_{6}\right)$ is $84^{\circ}$. The direction of the main anisotropy axes on each Dy"ll ion are following each other, thus forming a circular pattern similar to earlier reported $\left\{\text { Dy }_{6}\right\}^{\mathrm{b}, 4 c}$ complexes, resulting in a toroidal magnetic moment. The presence of ferromagnetic dipolar coupling and the $S_{6}$ symmetry of the complexes results in a negligible (or zero) magnetic moment $\left(0.0003 \mu_{\mathrm{B}}\right)$ in the ground coupled states, again similar to that reported for other $\left\{D_{6} y_{6}\right.$ examples. ${ }^{4 b}, 4 c$ Thus, 4 is categorised as an SMT displaying a net toroidal moment. ${ }^{30}$ Here, the ferromagnetic dipolar coupling is smaller $\left(+1.1 \mathrm{~cm}^{-1}\right)$ compared to the reported antiferromagnetic dipolar coupling $\left(-4.2 \mathrm{~cm}^{-1}\right.$ and $\left.-9.2 \mathrm{~cm}^{-1}\right)$ for $\left\{D y_{6}\right\} .4 b, 4 c$ The extra $-\mathrm{CH}_{2}$ - arm in the teaH ${ }_{3}$ ligand $\left(\mathrm{pdeaH}_{3}\right)$ utilised in the synthesis of 4 results in a smaller tilt angle $\left(\theta=\sim 38^{\circ}<54.75^{\circ}\right)$, which leads to the ferromagnetic dipolar coupling. Whereas this angle was found to be $73^{\circ}$ and $87.4^{\circ}$ for the parent $\left\{\mathrm{Dy}_{6}\right\}$ complexes. ${ }^{4 b, 4 c}$ The local anisotropy axes are found to be nearly in the plane of the molecule at $84^{\circ}$ from the $\mathrm{S}_{6}$ symmetry, however, the smaller dipolar coupling does not improve the stabilization energy of the ground toroidal magnetic state that lie $4.2 \mathrm{~cm}^{-1}$ below the excited states $\left(4.8 \mathrm{~cm}^{-1}\right.$ and $4.4 \mathrm{~cm}^{-1}$ for previously reported $\left\{\mathrm{Dy}_{6}\right\}$ complexes). ${ }^{4 \mathrm{~b}, 4 \mathrm{c}}$

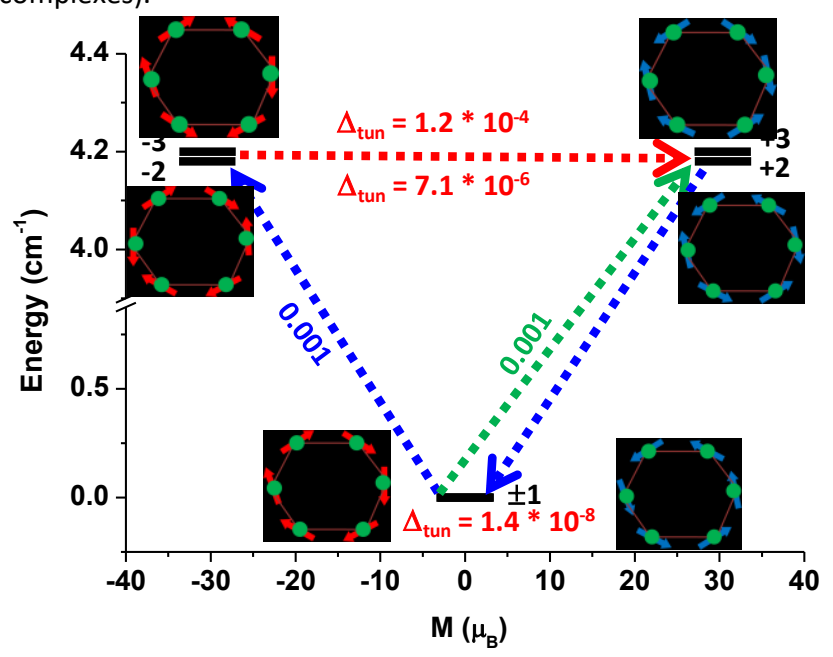

Figure 9. Low-lying exchange spectrum in 4 Dy $\left._{6}\right\}$. The exchange states are placed on the diagram per their magnetic moments (bold black lines). The red arrows show the tunnelling transitions within each doublet state, while the green/blue arrows show the possible pathway through Orbach/Raman relaxation. The numbers at the paths are averaged transition moments in $\mu_{\mathrm{B}}$, connecting the corresponding states. At few energy levels it provides a graphical representation of one of the corresponding non-collinear Ising quantum states, where the red/blue thick arrows at the $\mathrm{Ln}^{\text {III }}$ sites indicate magnetic moment direction in toroidal form.

\section{Toroidal Magnetic Behaviour of $\left\{\operatorname{Ln}^{\prime \prime \prime}{ }_{3}\right\}$ and $\left\{\operatorname{Ln}^{\prime \prime \prime}{ }_{6}\right\}$}

The studied $\left\{\mathrm{Ln}^{\prime \prime \prime}\right\}$ triangular and a $\left\{\mathrm{Ln}^{\prime \prime \prime}{ }_{6}\right\}$ wheel complexes satisfy the two necessary criteria required for a complex to display SMT behaviour: (a) the planar arrangement of local anisotropy axes and (b) the cyclic symmetry of the polynuclear Ln'"I complex. Moreover, the exchange and dipolar interaction between lanthanide ions decide the stabilization energy of their toroidal magnetic states.

The toroidal magnetic moment in the ground state of $\mathbf{2}\left\{\mathrm{Dy}^{\prime \mathrm{II}_{3}}\right\}$ is $6.4 \mu_{\mathrm{B}}$ which is three-times smaller compared to that calculated for the first archetypal $\left\{\mathrm{Dy}^{\prime \prime \prime}{ }_{3}\right\} \mathrm{SMT}$, which has a value of $19.7 \mu_{\mathrm{B}}$. Our calculations also predict toroidal behaviour for $\left\{\mathrm{Tb}^{\prime I_{3}}\right\}$ and $\left\{\mathrm{Ho}^{\prime \prime \prime}{ }_{3}\right\}$ triangles. The presence of conventional magnetic moments of $0.9 \mu_{\mathrm{B}}$, $6.4 \mu_{\mathrm{B}}$ and $6.0 \mu_{\mathrm{B}}$ with $C_{3}$ symmetry for $\mathbf{1 , 2}$ and $\mathbf{3}$, respectively makes them mixed-moment SMTs. ${ }^{30}$ Whereas, previously reported $\left\{\mathrm{Tb}_{6}\right\}$, $\left\{\mathrm{Dy}_{6}\right\}$ and $\left\{\mathrm{Ho}_{6}\right\}$ wheels posses negligible or no magnetic moments of $0.4 \mu_{B}, 0.003-0.005 \mu_{B}$ and $0.5 \mu_{B}$, respectively with higher $S_{6}$ symmetry makes them net toroidal moment SMTs. ${ }^{4 b}, 4 c$ Toroidal behaviour is rare in non-Kramer ions and thus $\mathbf{1}$ and $\mathbf{3}$ are the first non-Kramer type mixed-moment type SMTs.

We show with 4 that by chemically modifying the amine polyalcohol ligand ( $\mathrm{pdeaH}_{3}$ vs tea $\mathrm{H}_{3}$ ) we can modify the magnetic behavior in two ways. Firstly, we observe that minor changes of the ligand field shift the toroidal magnetic stabilization energy. However, we observe a reduction in the stabilization energy for $\mathbf{4}$ (toroidal ground to nontoroidal excited state) compared to our earlier reported $\left\{\mathrm{Dy}_{6}\right\}$

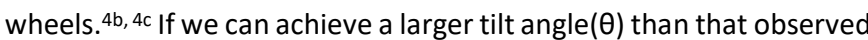
for the parent $\left\{\mathrm{Dy}_{6}\right\}$ complex, then a greater energy separation is expected. ${ }^{4 b}$, 4c Unfortunately, for 4, a smaller tilt angle resulted in weak ferromagnetic dipolar coupling, reducing the toroidal ground state stabilisation energy. We do note, however, that 4 shows a larger stabilization energy $\left(4.2 \mathrm{~cm}^{-1}\right)$ compared to the $\left\{D_{6}\right\}$ wheel reported by Powell et al utilizing the ligand 2,2'-(3aminopropylazanediyl) diethanol $\left(\mathrm{apadH}_{4}\right)$, reported as $2.1 \mathrm{~cm}^{-1}(3$ K). ${ }^{4 a}$ Since the stabilization energy was not calculated using $a b$ initio calculations, we compared the magnetization blockade value of their $\left\{\right.$ Dy $\left._{6}\right\}$ complex estimated using ac plots and it is noteworthy that the stabilization energy of toroidal magnetic states could not be more than this. Secondly, a imaginary component for $\mathbf{4}$ is observed in the ac susceptibility curves, as seen for previously reported $\left\{\mathrm{Dy}_{6}\right\}$ wheels. ${ }^{4 b, c}$ However, whereas the previous $\left\{D_{6}\right\}$ complexes do not show any peak maxima in the $\chi^{\prime \prime}$ vs. T curves, compound $\mathbf{4}$ has a significantly higher blocking temperature, showing a well-defined maximum in $\chi^{\prime \prime}$ under a zero and a 3000 Oe applied dc field. We therefore show that minor modifications of the ligand field can improve SMM properties. We see that the improved SMM behaviour, shown from experiment for $\mathbf{4}$, is in line with our ab initio analysis as $\mathbf{4}$ displays the smallest energy gap between the toroidal and ferromagnetic states $\left(4.2 \mathrm{~cm}^{-1}\right.$ vs 4.8 and $\left.4.4 \mathrm{~cm}^{-1}\right)$. As the nonmagnetic zero-field ground state can not support the slow relaxation, the SMM properties are superior when the ferromagnetic 
arrangement is achieved and these are easier to achieve when the aforementioned gap is smaller as seen in the case of 4 .

\section{Conclusions}

We report the synthesis, magnetic properties and theoretical predictions of three triangular complexes, $\left[\operatorname{Ln}_{3}{ }_{3}(\mathrm{OH})\left(\text { teaH }_{2}\right)_{3}(\text { paa })_{3}\right] \mathrm{Cl}_{2}(\mathrm{Ln}=\mathrm{Tb}(\mathbf{1})$, Dy (2) and Ho (3)), and a new wheel-type compound [Dy"lI 6 (pdeaH $\left.)_{6}\left(\mathrm{NO}_{3}\right)_{6}\right] \cdot 5 \mathrm{H}_{2} \mathrm{O}$ (4). The $\mathrm{M}$ vs. $\mathrm{H}$ plots at low fields at $2 \mathrm{~K}$ revealed an S-shaped curve for $\mathbf{1}$ and $\mathbf{4}$ which indicates the presence of a toroidal moment, whereas, such an S-shape not observed for $\mathbf{2}$ and $\mathbf{3}$. However, $a b$ initio calculations suggest a toroidal behaviour for all four complexes. The triangular complexes $\mathbf{1}$ - $\mathbf{3}$ display a mixed moment type SMT behaviour and the hexanuclear wheel $\mathbf{4}$ displays a net toroidal magnetic moment. The stabilization energy of the toroidal magnetic state in $\left\{D y_{6}\right\}(4)$ is found to be $4.2 \mathrm{~cm}^{-1}$ which is smaller compared to the earlier reported $\left\{\mathrm{Dy}_{6}\right\}$ complexes $\left(4.4 \mathrm{~cm}^{-1} \text { and } 4.8 \mathrm{~cm}^{-1}\right)^{4 \mathrm{~b}, \mathrm{c}}$ due to weaker ferromagnetic dipolar coupling. Our combined theoretical and experimental studies suggest that $a b$ initio calculations are key in determining the toroidal behaviour in molecular complexes. While other unambiguous experimental determinations of such toroidal states, using, for example NMR spectroscopy have been proposed, such measurements are very rare on such systems and are urgently needed to offer insight into the toroidal magnetic behaviour of various lanthanide clusters.

\section{Conflicts of interest}

There are no conflicts to declare.

\section{Acknowledgements}

GR would like to thank SERB (CRG/2018/000430) for the funding and IITB for generous high performance computing facilities. KSM would like to thank the Australian Research Council for funding. KRV would like to thank the IIT Bombay for a Research Associate (RA) position. TG is indebted to the UGC for providing financial assistance to conduct research activities.

\section{References}

1. J. Tang, I. Hewitt, N. T. Madhu, G. Chastanet, W. Wernsdorfer, C. E. Anson, C. Benelli, R. Sessoli and A. K. Powell, Angew. Chem. Int. Ed., 2006, 45, 1729-1733.

2. (a) L. F. Chibotaru, L. Ungur and A. Soncini, Angew. Chem. Int. Ed. 2008, 47, 4126-4129; (b) S.-Y. Lin, W. Wernsdorfer, L. Ungur, A K. Powell, Y.-N. Guo, J. Tang, L. Zhao, L. F. Chibotaru and H.-J. Zhang, Angew. Chem. Int. Ed., 2012, 51, 12767-12771; (c) A Soncini and L. F. Chibotaru, Phys. Rev. B, 2008, 77, 220406; (d) P.H. Lin, T. J. Burchell, L. Ungur, L. F. Chibotaru, W. Wernsdorfer and M. Murugesu, Angew. Chem. Int. Ed., 2009, 48, 9489-9492 (e) D. Gatteschi, R. Sessoli and L. Sorace, in Handbook on the Physics and Chemistry of Rare Earths, eds. G. B. Jean-Claude and K. P. Vitalij, Elsevier, 2016, vol. 50, pp. 91-139; (f) J. Luzon, K. Bernot, I. J. Hewitt, C. E. Anson, A. K. Powell and R. Sessoli, Phys. Rev. Lett., 2008, 100, 247205; (g) M. Gysler, F. El Hallak, L. Ungur, R. Marx, M. Hakl, P. Neugebauer, Y. Rechkemmer, Y. Lan, I.
Sheikin, M. Orlita, C. E. Anson, A. K. Powell, R. Sessoli, L. F. Chibotaru and J. van Slageren, Chem. Sci., 2016, 7, 4347-4354.

3. (a) A. I. Popov, D. I. Plokhov and A. K. Zvezdin, Phys. Rev. B, 2016, 94, 184408; (b) C. Das, S. Vaidya, T. Gupta, J. M. Frost, M. Righi, E. K. Brechin, M. Affronte, G. Rajaraman and M. Shanmugam, Chem. Eur. J., 2015, 21, 15639-15650.

4. (a) A. Baniodeh, N. Magnani, S. Brase, C. E. Anson and A. K. Powell, Dalton Trans., 2015, 44, 6343-6347; (b) S. K. Langley, K. R. Vignesh, B. Moubaraki, G. Rajaraman and K. S. Murray, Chem. Eur. J., 2019, 25, 4156-4165; (c) L. Ungur, S. K. Langley, T. N. Hooper, B. Moubaraki, E. K. Brechin, K. S. Murray and L. F. Chibotaru, J. Am. Chem. Soc., 2012, 134, 18554-18557.

5. G. Fernandez Garcia, D. Guettas, V. Montigaud, P. Larini, R. Sessoli, F. Totti, O. Cador, G. Pilet and B. Le Guennic, Angew. Chem. Int. Ed., 2018, 57, 17089-17093.

6. G. Novitchi, G. Pilet, L. Ungur, V. V. Moshchalkov, W. Wernsdorfer, L. F. Chibotaru, D. Luneau and A. K. Powell, Chem. Sci., 2012, 3, 1169-1176.

7. J. Wu, X.-L. Li, M. Guo, L. Zhao, Y.-Q. Zhang and J. Tang, Chem. Commun., 2018, 54, 1065-1068.

8. K. R. Vignesh, A. Soncini, S. K. Langley, W. Wernsdorfer, K. S. Murray and G. Rajaraman, Nat. Commun., 2017, 8, 1023.

9. K. R. Vignesh, S. K. Langley, A. Swain, B. Moubaraki, M. Damjanović, W. Wernsdorfer, G. Rajaraman and K. S. Murray, Angew. Chem. Int. Ed., 2018, 57, 779-784.

10. (a) E. Coronado and A. J. Epstein, J. Mater. Chem., 2009, 19, 1670 1671; (b) M. N. Leuenberger and D. Loss, Nature, 2001, 410, 789793.

11. L. Bogani and W. Wernsdorfer, Nat. Mater., 2008, 7, 179-186.

12. G. Sheldrick, Acta Crystallogr. Sect. A, 2008, 64, 112-122.

13. G. M. Sheldrick, SHELXL-97, Programs for X-ray Crystal Structure Refinement; , 1997, University of Göttingen: Göttingen, Germany, .

14. L. J. Barbour, J. Supramol. Chem., 2001, 1, 189-191.

15. F. Aquilante, T. B. Pedersen, V. Veryazov and R. Lindh, WIRES Comput. Mol. Sci., 2013, 3, 143-149.

16. B. O. Roos, R. Lindh, P.-A. Malmqvist, V. Veryazov, P.-O. Widmark and A. C. Borin, J. Phys. Chem. A, 2008, 112, 11431-11435.

17. B. A. Hess, C. M. Marian, U. Wahlgren and O. Gropen, Chem. Phys. Lett., 1996, 251, 365-371.

18. B. O. Roos and P.-A. Malmqvist, Phys. Chem. Chem. Phys., 2004, 6, 2919-2927.

19. L. F. Chibotaru and L. Ungur, J. Chem. Phys., 2012, 137, 064112 064122.

20. (a) L. F. Chibotaru, L. Ungur, C. Aronica, H. Elmoll, G. Pilet and D. Luneau, J. Am. Chem. Soc., 2008, 130, 12445-12455; (b) H. L. C. Feltham, R. Clérac, L. Ungur, V. Vieru, L. F. Chibotaru, A. K. Powell and S. Brooker, Inorg. Chem., 2012, 51, 10603-10612; (c) P.-H. Guo, J.-L. Liu, Z.-M. Zhang, L. Ungur, L. F. Chibotaru, J.-D. Leng, F.S. Guo and M.-L. Tong, Inorg. Chem., 2012, 51, 1233-1235; (d) J.L. Liu, J.-Y. Wu, G.-Z. Huang, Y.-C. Chen, J.-H. Jia, L. Ungur, L. F. Chibotaru, X.-M. Chen and M.-L. Tong, Scientific Reports, 2015, 5, 16621; (e) S. K. Langley, N. F. Chilton, L. Ungur, B. Moubaraki, L. F. Chibotaru and K. S. Murray, Inorg. Chem., 2012, 51, 1187311881; (f) S. K. Langley, N. F. Chilton, B. Moubaraki and K. S. Murray, Inorg. Chem. Front., 2015, 2, 867-875; (g) S. K. Langley, L. Ungur, N. F. Chilton, B. Moubaraki, L. F. Chibotaru and K. S. Murray, Inorg. Chem., 2014, 53, 4303-4315; (h) S. K. Langley, N. F. Chilton, B. Moubaraki and K. S. Murray, Chem. Commun., 2013, 49, 6965-6967; (i) P. H. Lin, N. C. Smythe, S. I. Gorelsky, S. Maguire, N. J. Henson, I. Korobkov, B. L. Scott, J. C. Gordon, R. T. Baker and M. Murugesu, J. Am. Chem. Soc., 2011, 133, 15806- 
15809; (j) J.-L. Liu, J.-Y. Wu, Y.-C. Chen, V. Mereacre, A. K. Powell, L. Ungur, L. F. Chibotaru, X.-M. Chen and M.-L. Tong, Angew. Chem. Int. Ed., 2014, 53, 12966-12970; (k) V. S. Mironov, L. F. Chibotaru and A. Ceulemans, J. Am. Chem. Soc., 2003, 125, 97509760; (I) L. Ungur, W. Van den Heuvel and L. F. Chibotaru, New J. Chem., 2009, 33, 1224-1230; (m) K. R. Vignesh, S. K. Langley, K. S. Murray and G. Rajaraman, Inorg. Chem., 2017, 56, 2518-2532; (n) S. Xue, L. Ungur, Y.-N. Guo, J. Tang and L. F. Chibotaru, Inorg. Chem., 2014, 53, 12658-12663.

21. M. E. Lines, J. Chem. Phys., 1971, 55, 2977-2984.

22. L. F. Chibotaru and L. Ungur, POLY_ANISO program, 2006, University of Leuven.

23. (a) J. Cirera, E. Ruiz and S. Alvarez, Chem. Eur. J., 2006, 12, 31623167; (b) M. Pinsky and D. Avnir, Inorg. Chem., 1998, 37, 55755582.

24. (a) Y.-S. Ding, R. Winpenny and Y.-Z. Zheng, Journal, 2018, DOI: 10.26434/chemrxiv.7083038; (b) T. Gupta and G. Rajaraman, Eur. J. Inorg. Chem., 2018, 2018, 3402-3412; (c) T. Gupta, G. Velmurugan, T. Rajeshkumar and G. Rajaraman, J. Chem. Sci., 2016, 128, 1615-1630; (d) K. R. Vignesh, D. I. Alexandropoulos, B. S. Dolinar and K. R. Dunbar, Dalton Trans., 2019, 48, 2872-2876.

25. N. F. Chilton, CC-fit, The University of Manchester, UK, 2014, http://www.nfchilton.com/cc-fit.html.

26. D. Sertphon, K. S. Murray, W. Phonsri, J. Jover, E. Ruiz, S. G. Telfer, A. Alkas, P. Harding and D. J. Harding, Dalton Trans., 2018, 47, 859-867.

27. K. N. Shrivastava, Phys. stat. sol. (b), 1983, 117, 437-458.

28. Y.-X. Wang, W. Shi, H. Li, Y. Song, L. Fang, Y. Lan, A. K. Powell, W. Wernsdorfer, L. Ungur, L. F. Chibotaru, M. Shen and P. Cheng, Chem. Sci., 2012, 3, 3366-3370.

29. (a) P. Panissod and M. Drillon, in Magnetism: Molecules to Materials IV, eds. J. S. Miller and M. Drillon, Wiley-VCH Verlag GmbH \& Co. KGaA, Weinheim, 2002, ch. 7, p. 235; (b) J.-D. Leng, J.-L. Liu, W.-Q. Lin, S. Gomez-Coca, D. Aravena, E. Ruiz and M.-L. Tong, Chem. Commun., 2013, 49, 9341-9343.

30. L. Ungur, S.-Y. Lin, J. Tang and L. F. Chibotaru, Chem. Soc. Rev., 2014, 43, 6894-6905. 